\title{
Lidar arc scan uncertainty reduction through scanning geometry optimization
}

\author{
Hui Wang ${ }^{1}$, Rebecca J. Barthelmie ${ }^{1}$, Sara C. Pryor ${ }^{2}$, and Gareth. Brown ${ }^{3}$ \\ ${ }^{1}$ Sibley School of Mechanical and Aerospace Engineering, Cornell University, Ithaca, New York, USA \\ ${ }^{2}$ Department of Earth and Atmospheric Sciences, Cornell University, Ithaca, New York, USA \\ ${ }^{3}$ SgurrEnergy Ltd, Vancouver, British Columbia, Canada \\ Correspondence to: Hui Wang (hw524@cornell.edu)
}

Received: 24 June 2015 - Published in Atmos. Meas. Tech. Discuss.: 7 October 2015

Revised: 13 February 2016 - Accepted: 1 April 2016 - Published: 13 April 2016

\begin{abstract}
Doppler lidars are frequently operated in a mode referred to as arc scans, wherein the lidar beam scans across a sector with a fixed elevation angle and the resulting measurements are used to derive an estimate of the $n$ minute horizontal mean wind velocity (speed and direction). Previous studies have shown that the uncertainty in the measured wind speed originates from turbulent wind fluctuations and depends on the scan geometry (the arc span and the arc orientation). This paper is designed to provide guidance on optimal scan geometries for two key applications in the wind energy industry: wind turbine power performance analysis and annual energy production prediction. We present a quantitative analysis of the retrieved wind speed uncertainty derived using a theoretical model with the assumption of isotropic and frozen turbulence, and observations from three sites that are onshore with flat terrain, onshore with complex terrain and offshore, respectively. The results from both the theoretical model and observations show that the uncertainty is scaled with the turbulence intensity such that the relative standard error on the 10 min mean wind speed is about $30 \%$ of the turbulence intensity. The uncertainty in both retrieved wind speeds and derived wind energy production estimates can be reduced by aligning lidar beams with the dominant wind direction, increasing the arc span and lowering the number of beams per arc scan. Large arc spans should be used at sites with high turbulence intensity and/or large wind direction variation.
\end{abstract}

\section{Introduction}

Coherent Doppler lidars (hereafter called lidars) have been used to probe a range of atmospheric boundary layer (ABL) phenomena, including nocturnal low level jets in the Great Plains (Banta et al., 2008), spatial variability of wind in the marine ABL (Pichugina et al., 2012), structures of the urban ABL (Calhoun et al., 2006; Frehlich et al., 2006) and turbulent properties and flow patterns over complex terrain (Krishnamurthy et al., 2011; Choukulkar et al., 2012). Lidars also have applications in wind energy resource estimation and wake characterization (Banta et al., 2013; Barthelmie et al., 2013) due to their ability to accurately and precisely measure flow structures both in front of and in the wake of a wind turbine (Simley et al., 2013; Aitken et al., 2014) and spatial variability of wind speeds over prospective wind farms $(\mathrm{Kr}-$ ishnamurthy et al., 2013).

Lidar measurements usually involve operating the instrument with a scan geometry to acquire radial velocities from at least three directions and estimating wind velocity according to the following equation:

$v_{\mathrm{r}}(s)=\boldsymbol{d}^{T} \boldsymbol{u}$,

where $\quad \boldsymbol{d}^{T}=[\cos \phi \sin \theta, \cos \phi \cos \theta, \sin \phi] \quad$ and $\quad \boldsymbol{u}^{T}=$ $[u, v, w$,$] . The radial velocity v_{\mathrm{r}}$ is the projection of the wind velocity $\boldsymbol{u}$ on the line of sight (LOS) at the location $\boldsymbol{s}=\boldsymbol{s} \boldsymbol{d}$ for which $s$ is the distance from the lidar along the LOS and $\boldsymbol{d}$ is the unit directional vector determined by the elevation angle $\phi$ and the azimuth angle $\theta$ of the LOS from north. The uncertainty or standard error of the estimated wind velocity has great importance to wind energy applications 
and is a function of the atmospheric turbulence structure and the specific lidar scanning geometry (Banakh et al., 1995). Two common scanning geometries applied in wind energy are the velocity-azimuth-display (VAD) scan and the arc scan. VAD scans apply a full-azimuth conical scan (i.e., $\theta$ from 0 to $360^{\circ}$ ) with a constant elevation angle $(\phi)$ and the wind velocity is estimated by solving Eq. (1) under the assumption of a horizontally homogeneous wind field. When the assumption is met VAD scans are reliable and well understood and can meet the stringent accuracy requirement for wind energy applications (Gottschall et al., 2012). The arc scan involves $\phi$ being held constant and $\theta$ varied to sample a conical sector (e.g., Henke and Clive, 2015). VAD scans are commonly used for wind resource assessment because in homogeneous terrain or under a constant wind gradient the function used to derive the wind velocity should have the smallest errors, while arc scans can potentially have large errors if the fit is distorted by a small number of erroneous points. However, arc scans "are less affected by inhomogeneities in the wind field on scales of the scan diameter than are the full circle scans" (Schwiesow et al., 1985). Arc scans have a role, especially if heterogeneous conditions exist, because the scan can be focused on the region of interest. For example, a VAD scan centered at the hub of an operating wind turbine will be affected by inhomogeneity because of the wind turbine wake. If the purpose of measurement is the freestream wind speed, a smaller sector scan or arc scan upwind of the wind turbine can be more suitable than a full conical scan. Arc scans also have the advantage that by only sampling the area of interest, the number of sample repetitions in a given time can be increased, decreasing the statistical uncertainty in solving Eq. (1). Use of arc scans adds two additional parameters to the scanning geometry: (1) the arc span (i.e., the width of the scan sector, $\Delta \theta$ ) and (2) the angle between the center of the arc and the wind direction, which is a measure of the orientation of the arc scan and will be called hereafter the relative direction and denoted as $\beta$. The selection of these parameters have implications for the accuracy of the retrieved wind speed (Courtney et al., 2014; Wang et al., 2015). Here we extend prior work on optimizing scan geometry to minimize the uncertainty in the estimated wind speeds. We present a quantitative analysis of the dependence of the retrieved wind speed uncertainty on scanning geometry and turbulence intensity, and provide a tool for use in planning lidar deployments for wind energy applications such as power performance tests. The analysis uses both a theoretical turbulence model and real arc scan measurements from a pulsed lidar deployed in three different geographic locations characterized by different surface roughness and turbulence regimes. We conclude by demonstrating how the wind speed uncertainty from lidar arc scan measurement is propagated to the uncertainty in predicting annual energy production (AEP).
Table 1. Galion G4000 Doppler wind lidar specification ${ }^{1}$.

\begin{tabular}{ll}
\hline Parameter & Value \\
\hline Wave length & $1.56 \mu \mathrm{m}$ \\
Pulse energy & $30 \mu \mathrm{J}$ \\
Pulse duration $^{2}$ & $200 \mathrm{~ns}(30 \mathrm{~m})$ \\
Range gate size & $30 \mathrm{~m}$ \\
Spatial Resolution & 3 \\
Aperture diameter & $60 \mathrm{~m}$ \\
Pulse repetition frequency & $75 \mathrm{~mm}$ \\
Sampling frequency & $100 \mathrm{kHz}$ \\
Dwell time & $1 \mathrm{~s}$ \\
Radial velocity accuracy & $0.1 \mathrm{~m} \mathrm{~s}{ }^{-1}$ \\
\hline${ }^{1}$ This specification is provided by SgurrEnergy. ${ }^{2}$ Full \\
width at half maximum. ${ }^{3}$ Spatial resolution is the sum of \\
the pulse duration and the range gate size (Frehlich, 1997).
\end{tabular}

\section{Uncertainty in the lidar radial velocity}

Uncertainties in measured radial velocities from a pulsed lidar (e.g., Sgurr's Galion lidar from which measurements are presented herein, Table 1) are well characterized (Frehlich and Yadlowsky, 1994; Frehlich, 1997) and can be described as follows:

$v_{\mathrm{R}}=v_{\mathrm{R} 0}+e+\delta$,

where $v_{\mathrm{R}}$ is the measured radial velocity, $v_{\mathrm{R} 0}$ is the true radial velocity in the sensing volume, $\delta$ is the bias due to systematic errors and $e$ is the random error which has zero mean and variance $\sigma_{\mathrm{e}}^{2}$. The magnitude of $\sigma_{\mathrm{e}}^{2}$ is a function of both the signal-to-noise ratio (SNR) and the radial velocity variance $\left(\sigma_{v_{\mathrm{r}}}^{2}\right)$ in the sensing volume. The true radial velocity from a range gate is well approximated by the weighted average of radial velocities in the sensing volume as (Frehlich, 1997):

$v_{\mathrm{R} 0}(r)=\int_{0}^{\infty} v_{\mathrm{r}}(s) W(r-s) \mathrm{d} s$,

where $r$ is the lidar range gate location on the LOS, and $W(r-s)$ is a weighting function with its peak value at $s=r$. Note that we use $v_{\mathrm{r}}$ to denote a radial velocity at a point location and $v_{\mathrm{R}}$ a measured (volumetrically averaged) radial velocity.

The precision of $v_{\mathrm{R}}$ is bounded by the Cramer-Rao Bound (CRB) which is a function of SNR (Pearson and Collier, 1999). The relationship between CRB and SNR derived from Eq. (5) in Pearson and Collier (1999), and that estimated from radial velocity measurements using the autocorrelation method from Frehlich (2001) are shown in Fig. 1 for the Galion lidar. Both show that CRB decreases exponentially with increasing SNR, and for the Galion lidar, $\sigma_{\mathrm{e}}^{2}$ has the lower bound of $0.01 \mathrm{~m}^{2} \mathrm{~s}^{-2}$ when SNR $>-20 \mathrm{~dB}$.

The uncertainty in $v_{\mathrm{R}}$ scales with turbulence intensity due to fluctuations of both wind speed and backscattering parti- 


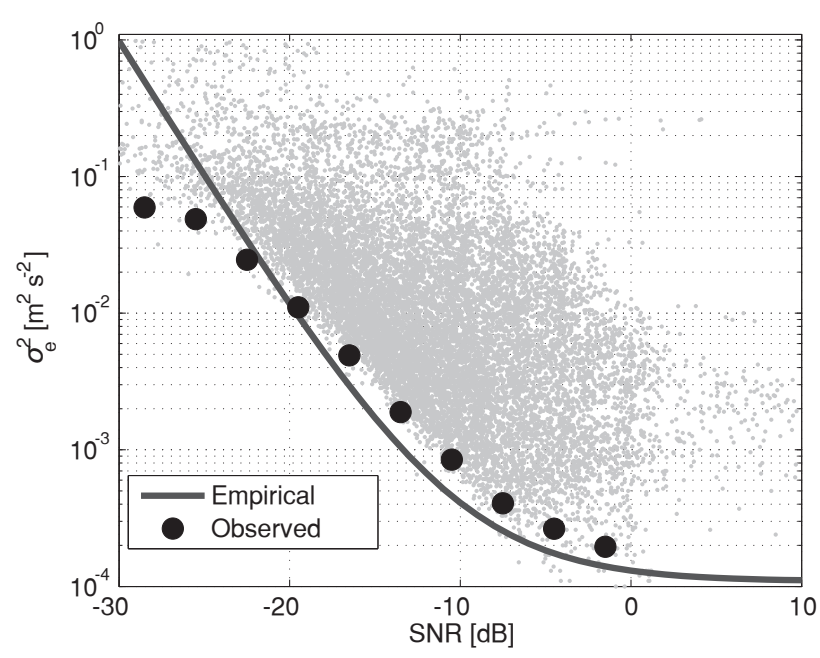

Figure 1. The relationship between the signal-to-noise ratio (SNR) and the radial velocity random error variance $\left(\sigma_{\mathrm{e}}^{2}\right)$. The gray dots show the observed radial velocity variance approximated by the difference between the variance and the autocovariance at one time lag of the radial velocities collected in an experiment in which the lidar was operated with a staring mode at the US National Renewable Energy Laboratory (Wang et al., 2015), and the observed CramerRao Bound (CRB) (filled dark circles) is approximated by the mean of the lowest $5 \%$ of the gray dots (Frehlich, 2001). The empirical relationship between the SNR and the CRB is denoted by the dark solid line and is based on Eq. (5) in Pearson and Collier (1999).

cle locations in the sensing volume can broaden the signal spectrum and thus increase the uncertainty in $v_{\mathrm{R}}$ (Banakh et al., 1995; Frehlich, 1997). When the turbulence is sufficiently strong $\left(\sigma_{v_{\mathrm{r}}} \geq 0.5 w_{\mathrm{R}}\right.$ where $w_{\mathrm{R}}$ is the spectrum width of lidar signal in velocity space that is $\sim 0.877 \mathrm{~m} \mathrm{~s}^{-1}$ for the Galion lidar), the random error variance $\sigma_{\mathrm{e}}^{2}$ becomes proportional to $\sigma_{v_{\mathrm{r}}}$. If $\sigma_{v_{\mathrm{r}}}$ is extremely large, the spectrum width will be such that the peak is indistinguishable from the noise and thus the radial velocity selected by an estimator can be any value within the velocity search space $\left( \pm 39 \mathrm{~m} \mathrm{~s}^{-1}\right.$ for the Galion lidar).

Other sources of error in $v_{\mathrm{R}}$ include non-linear vertical wind shear which can introduce a bias in radial velocity measurement (Lindelöw et al., 2008), and lidar misalignment which results in incorrect azimuth and elevation angles so the measured radial velocity does not represent the wind field at the intended location. For a well-secured ground-based lidar pitch (displacement from the horizontal) and roll (i.e., "tilt") angles can be measured and are usually much lower than $1^{\circ}$, causing negligible errors.

The synthesis given above thus indicates that when SNR is reasonably high, the uncertainty in $v_{\mathrm{R}}$ is small $\left(\sigma_{\mathrm{e}}^{2}<\right.$ $0.01 \mathrm{~m}^{2} \mathrm{~s}^{-1}$ ), and makes a much smaller contribution to the overall uncertainty in the derived horizontal wind speed than turbulent wind fluctuations in the sampling volume (as shown in the next section). Hence, the uncertainty in $v_{\mathrm{R}}$ will not be considered further in calculating the uncertainty in the estimated mean wind speed from arc scans.

\section{Uncertainty in wind speeds derived from lidar arc scan measurements}

As in other Eulerian measurement systems (e.g., a network of anemometers deployed on meteorological masts), a lidar conducting arc scans measures the wind velocity by sampling the wind field with a specified sampling frequency and spatial coverage, but the lidar only measures the radial velocity, and wind velocity needs to be estimated using an inverse method applied under certain assumptions about the wind field. When the radial velocity has negligible errors, the uncertainty in the estimated wind velocity is controlled by (1) the spatial statistics of the wind field that determine the variation of and the correlation between the samples (and hence effective sample size, and the representativeness of the wind field), (2) the scanning geometry that determines the temporal and spatial resolution of the samples and (3) the stability of the inverse method. In this section, we describe how the uncertainty in the estimated mean horizontal wind speed from arc scans (denoted as $V_{1}$ ) is related to the characteristics of the wind field and the scanning geometry. The method used follows that of Banakh et al. (1995) which was developed to evaluate the uncertainty of wind velocities estimated from VAD scans.

In a homogeneous and stationary wind field, the covariance between the $i$ th and $j$ th radial velocities, which are measured by a lidar at the range gates centered at $\boldsymbol{r}_{i}=r_{i} \boldsymbol{d}$ and $\boldsymbol{r}_{j}=r_{j} \boldsymbol{d}$, respectively, is a function of the relative location between these two measurements. With the assumption of frozen turbulence, the relative location between the two measurements is $\boldsymbol{p}_{i j}=\boldsymbol{r}_{i}-\boldsymbol{r}_{j}-\Delta \boldsymbol{p}_{i j}$ where $\Delta \boldsymbol{p}_{i j}=[(i-$ $j) \delta t] \boldsymbol{u}_{0}$ is the separation distance induced by the mean wind velocity $\boldsymbol{u}_{0}=\left(u_{0}, v_{0}, w_{0}\right)$ during a time interval $(i-j) \delta t$. The covariance between the two radial velocity measurements $\left(a_{i j}\right)$ then can be written as follows:

$a_{i j}\left(\boldsymbol{p}_{i j}\right)=\iint_{0}^{\infty}\left[W\left(s_{i}-r_{i}\right) W\left(s_{j}-r_{j}\right) K_{\mathrm{r}}\left(\boldsymbol{q}_{i j}\right)\right] \mathrm{d} s_{i} \mathrm{~d} s_{j}$,

where $\boldsymbol{q}_{i j}=\boldsymbol{s}_{i}-\boldsymbol{s}_{j}-\Delta \boldsymbol{p}_{i j}$. The term $K_{\mathrm{r}}\left(\boldsymbol{q}_{i j}\right)$ is the covariance between the point radial velocities $\left(v_{\mathrm{r}}\right)$ separated by $\boldsymbol{q}_{i j}$ that is related to the covariance matrix $\mathbf{C}\left(\boldsymbol{q}_{i j}\right)$ of wind velocities with the same separation distance:

$K_{\mathrm{r}}\left(\boldsymbol{q}_{i j}\right)=\boldsymbol{d}_{i}^{T} \mathbf{C}\left(\boldsymbol{q}_{i j}\right) \boldsymbol{d}_{j}$.

The entries in the covariance matrix $\mathbf{C}$ are the ensemble variance and covariance between three orthogonal wind components. Note no summation is assumed over repeated indices in Eqs. (4) and (5). Let $\mathbf{A}$ denote the covariance matrix for all measured radial velocities within a $10 \mathrm{~min}$ period. The 


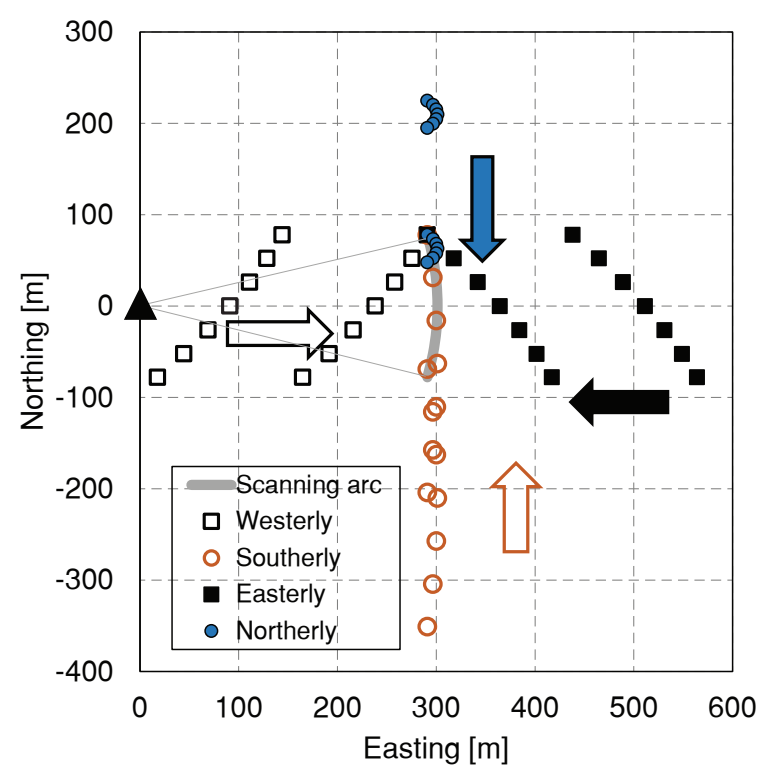

Figure 2. An example of the spatial distribution of air parcels sampled in two consecutive arc scans by a lidar at range distance $s=315 \mathrm{~m}$ for four different wind directions (westerly, easterly, northerly, and easterly) under the following assumptions: (1) frozen turbulence, (2) the lidar is located at the origin (the dark triangle) scanning from $\theta=75$ to $105^{\circ}$ with $5^{\circ}$ increments with elevation angle $\phi=17^{\circ}$, (3) the mean wind speed is $7 \mathrm{~m} \mathrm{~s}^{-1}$ and (4) the sampling interval is $3 \mathrm{~s}$.

entry of $\mathbf{A}$ at $i$ th row and $j$ th column is defined by Eq. (4). For a given scanning geometry, Eqs. (4) and (5) show that, apart from the atmospheric turbulence structure, the statistics of the measured radial velocities are controlled by the mean wind field because the separation distance $\Delta \boldsymbol{p}_{i j}$ or $\Delta \boldsymbol{q}_{i j}$ varies with the mean wind speed and direction (as illustrated in Fig. 2). When the relative direction of the lidar beam $\beta=0^{\circ} / 180^{\circ}$ (westerly/easterly in Fig. 2), the samples are located in a rectangular area swept by the wind over the arc. When $\beta= \pm 90^{\circ}$, the samples are from a line aligned with the arc. If the scan direction is the same as the wind (i.e., $\beta=+90^{\circ}$ ), the samples from one arc scan are clustered and almost from the same location (northerly in Fig. 2). When $\beta=-90^{\circ}$, the locations sampled by one arc are more spatially extended (southerly in Fig. 2).

The uncertainty in the wind velocity estimated from arc scans can be derived from the covariance matrix $\mathbf{A}$ of the measured radial velocities. Assuming a horizontally homogeneous wind field with zero mean vertical wind speed (i.e., $\left.w_{0}=0\right)$, the solution of the ordinary least squares $\left(V_{1}\right)$ based on Eq. (1) is the estimate of horizontal wind velocity (Wang et al., 2015):

$\boldsymbol{V}_{1}=\mathbf{G} \boldsymbol{v}_{\mathrm{R}}$

where $\mathbf{G}=\left(\mathbf{D}^{\mathrm{T}} \mathbf{D}\right)^{-1} \mathbf{D}^{\mathrm{T}}$ and $\boldsymbol{v}_{\mathrm{R}}$ is a vector including $N$ radial velocities measured in, for example, $10 \mathrm{~min}$. The matrix $\mathbf{D}$ is a $N \times 2$ matrix with its $i$ th row given by $\left[\cos \phi \sin \theta_{i}, \cos \phi \cos \theta_{i}\right]$. The estimated wind velocity $\boldsymbol{V}_{1}$ comprises horizontal components, $\boldsymbol{V}_{1}=\left(u_{1}, v_{1}\right)$. The uncertainty in $V_{1}$ is characterized by its covariance matrix $\left(\mathbf{C}_{1}\right)$ given by

$\mathbf{C}_{1}=\mathbf{G A G}^{\mathrm{T}}$,

assuming zero random error for radial velocity (Wang et al., 2015). The variance of the random error $\sigma_{\mathrm{e}}^{2}$ is $\sim 0.01 \mathrm{~m}^{2} \mathrm{~s}^{-2}$ (see Sect. 2) which is much smaller than the diagonal terms of $\mathbf{A}\left(>0.1 \mathrm{~m}^{2} \mathrm{~s}^{-2}\right.$ given wind speed $>4 \mathrm{~ms}^{-1}$ and turbulence intensity $\approx 10 \%$ ); therefore, it can be neglected. For most applications, the desired output from arc scans is the horizontal wind speed $\left(V_{1}\right)$ that is estimated as

$V_{1}=\sqrt{u_{1}^{2}+v_{1}^{2}}$.

The uncertainty in $V_{1}$ as quantified by the standard error $\left(\sigma_{1}\right)$ can be approximated as (Lyons, 1991):

$\sigma_{1}=\left[\left(u_{1} \sigma_{\mathrm{lu}}\right)^{2}+\left(v_{1} \sigma_{\mathrm{lv}}\right)^{2}+2\left(\rho_{u v} \sigma_{\mathrm{lu}} \sigma_{\mathrm{lv}}\right)\left(u_{1} v_{1}\right)\right]^{0.5} / V_{1}$,

where $\sigma_{\mathrm{lu}}^{2}$ and $\sigma_{\mathrm{lv}}^{2}$ represent the variance of $u_{1}$ and $v_{1}$ and can be found from the diagonal of $\mathbf{C}_{1}$, respectively. The term $\rho_{u v}$ in Eq. (9) is the correlation between $u_{1}$ and $v_{1}$, and $\rho_{u v} \sigma_{\mathrm{lu}} \sigma_{\mathrm{lv}}$ is the covariance that is given by the only non-diagonal term in $\mathbf{C}_{1}$. The value of $\sigma_{1}$ can be estimated from the observational data using Eq. (7) with the diagonal terms in $\mathbf{A}$ being approximated by $v_{\mathrm{R}}$ variance derived from measurements and the off-diagonal terms being zero (i.e., assuming no correlation between the measured radial velocities) (Wang et al., 2015).

\section{Uncertainty computed from an isotropic turbulence model}

Following the background presented in Sect. 3 above, the uncertainty in a 10 min mean wind speed estimated from lidar arc scans is analyzed as a function of (1) turbulence intensity, (2) mean wind speed and direction, and (3) scanning geometry using an isotropic turbulence model. For isotropic turbulence the covariance of the measured radial velocities in Eq. (4) can be calculated as follows: the entry at the $l$ th row and $k$ th column $(l, k=1,2,3)$ of the covariance matrix $\mathbf{C}(\boldsymbol{q})$ in Eq. (5) is given by the following equation (Monin and Yaglom, 1965)

$c_{\mathrm{lk}}(\boldsymbol{q})=c_{u}(q) \delta_{l k}+\frac{1}{2} q \frac{\mathrm{d} c_{u}}{\mathrm{~d} q}\left(\delta_{\mathrm{lk}}-\frac{q_{l} q_{k}}{q^{2}}\right)$,

where $q=|\boldsymbol{q}|, q_{1}, q_{2}$ and $q_{3}$ are the separation distances in the streamwise, transverse and vertical directions, respectively, and $\delta_{\mathrm{lk}}$ is the Kronecker delta. The streamwise wind component spatial covariance function $c_{u}(q)$ can be approximated by the exponential decay function

$c_{u}(q)=\sigma_{u}^{2} \exp \left(-\frac{q}{L_{u}}\right)$, 
where $\sigma_{u}^{2}$ is the streamwise velocity variance, and $L_{u}$ is the turbulence integral length scale which can be calculated from turbulence intensity $\left(\mathrm{TI}=\sigma_{u} / V_{0}\right)$ in a neutrally stratified atmospheric boundary layer (see Appendix A). Note that Eq. (11) misrepresents properties of turbulence of small scales and thus is not consistent with the von Kármán model used to calculate $L_{u}$ in Appendix A, but it has similar accuracy to the von Kármán model in predicting the uncertainty of wind speed from conical scans (Banakh et al., 1995). Thus, Eq. (11) is used here for its simplicity and effectiveness. For a given wind speed and direction, the separation distance vector $\boldsymbol{q}$ can be calculated from $\phi, \delta \theta$ and $r$, and the point radial velocity covariance defined in Eq. (5) can be derived from Eqs. (10) and (11). Then the covariance of the measured radial velocities can be calculated by defining a weighting function in Eq. (4). In this analysis the weighting function is approximated by a triangular weighting function defined as

$W(r-s)=\max \left[0, \frac{2}{\Delta R}\left(1-\frac{2}{\Delta R}|r-s|\right)\right]$,

where $\Delta R$ is the spatial extent of $v_{\mathrm{R}}$ along the LOS, which is a function of the lidar pulse length and hence the illuminated volume at the time of measurement. For the Galion $\Delta R=60 \mathrm{~m}$ according to Frehlich (1997) and the lidar parameters in Table 1 . The radial velocity covariance matrix $\mathbf{A}$ in Eq. (7) is calculated for $N$ measured radial velocities and used in Eq. (9) for calculation of the associated uncertainty in $V_{1}$ which is presented here as the relative standard error (abbreviated as lidar RSE and denoted by $\varepsilon_{1}$ ) defined as the ratio of the standard error of the estimated mean horizontal wind speed $\left(\sigma_{1}\right)$ to the true mean horizontal wind speed $\left(V_{0}\right)$ :

$\varepsilon_{1}=\frac{\sigma_{1}}{V_{0}}$.

The magnitude of $\varepsilon_{1}$ is a function of TI, mean wind speed and direction. Note that $\varepsilon_{1}$ is inversely proportional to $\Delta R / L_{u}$ which determines the amount of averaging taken for $v_{\mathrm{R}}$ (see Eq. 3). For a given $L_{u}$, a larger $\Delta R$ implies an average over a bigger area, and therefore less variation in the measured radial velocity and less uncertainty in the estimated wind velocity. Because $L_{u}$ is defined as a function of TI and height (see Appendix $\mathrm{A}$ ) and only one lidar with a constant $\Delta R$ is investigated here, the dependence of $\varepsilon_{1}$ on $\Delta R / L_{u}$ is not considered hereafter.

The relative importance of these functional dependencies and relevance to wind energy applications can be demonstrated using an example in which a lidar is used for a power performance test of a turbine. This type of test is undertaken to determine if the turbine is operating according to the specified power curve (i.e., production of electricity as a function of the inflow wind speed) and thus it involves measurements of the incident flow into the turbine rotor (Wagner et al., 2011). When lidars are used for this purpose they are typically deployed to measure with arc scans at the hub
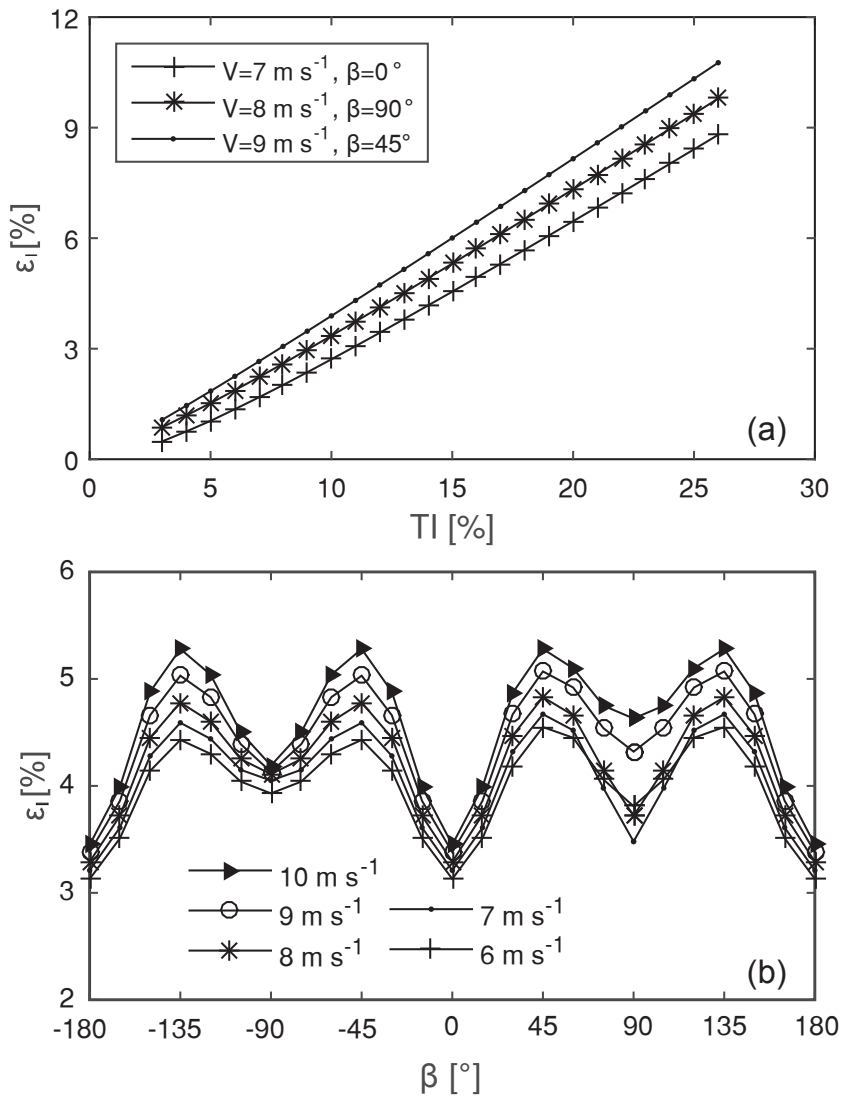

Figure 3. Dependence of the relative standard error $\left(\varepsilon_{1}\right)$ of wind speed estimated from arc scans on (a) turbulence intensity (TI) and (b) wind speed $\left(V_{0}\right)$ and direction (expressed as the relative direction $(\beta)$ ) based on the isotropic turbulence model given in Eq. (10) for the following scan geometry: $\phi=16.7^{\circ}, \Delta \theta=30^{\circ}, \delta \theta=6^{\circ}$ and $r=313 \mathrm{~m}$. The Coriolis parameter $f_{0}=0.0001 \mathrm{~s}^{-1}$.

height 2-4 rotor diameters in front of the wind turbine (IEC, 2005). Assuming that the hub height is $90 \mathrm{~m}$, the rotor diameter is $90 \mathrm{~m}$, and the lidar placed at the base of the turbine is operated with a fixed elevation angle of $16.7^{\circ}$ to measure wind velocities 3 rotor diameters in front of the turbine at hub height (i.e., $r=313 \mathrm{~m}$ ). The arc scan is defined using a span of $\Delta \theta$ comprising $M_{\theta}$ azimuth angles. It takes $\delta t \mathrm{~s}$ to finish one measurement at one azimuth angle and move $\delta \theta$ to the next azimuth angle, so the sampling intervals are $\delta t$ in time and $\delta \theta$ in space. As a result, one arc scan takes $M_{\theta} \delta t \mathrm{~s}$ and the total number of arc scans conducted in $10 \mathrm{~min}$ is $M_{10}=600 / M_{\theta} \delta t$. For the power performance test scenario described above typical parameters would be: $\delta t=3 \mathrm{~s}, \Delta \theta=30^{\circ}$ and $\delta \theta=6^{\circ}$. For reasonable values of TI and $V_{0}$, using the isotropic turbulence model and the definition of the dominant length scale $L_{u}$ in Appendix A, RSE $\left(\varepsilon_{1}\right)$ shows strongest dependence on TI (Fig. 3a), and increases from about $1.5 \%$ for $V_{0}=7-9 \mathrm{~m} \mathrm{~s}^{-1}$ at $\mathrm{TI}=5 \%$ (a low turbulence environment such as might be experienced offshore) to 6-9\% for $\mathrm{TI}>20 \%$ (i.e., a high turbulence en- 
vironment). RSE also increases with increasing wind speed through its relationship with the variance. The RSE $\left(\varepsilon_{1}\right)$ for $\mathrm{TI}=12 \%$, for a range of wind speed $\left(V_{0}\right)$ and relative direction $(\beta)$ from -180 to $180^{\circ}$, indicates that under the assumption of isotropic turbulence $\varepsilon_{1}$ varies with $\beta$ but the variation is no more than $\pm 2 \%$ for the range of conditions shown in Fig. 3b. The relationships shown in Fig. $3 b$ are expected because the sample locations and resulting spatial correlations between the samples are determined by wind speed and direction (see Fig. 2). RSE reaches its minimum at $\beta=0$ and $180^{\circ}$ and exhibits the lowest dependence on wind speed. The maximum $\varepsilon_{1}$ occurs at $\beta= \pm 45$ and $\pm 135^{\circ}$ and exhibits a much stronger dependence on wind speed. When $\beta= \pm 90^{\circ}, \varepsilon_{1}$ reaches local minima and has a relatively large difference between $\beta=-90^{\circ}$ and $\beta=+90^{\circ}$ because of the different spatial distribution and thus spatial correlation of samples between $\beta=-90^{\circ}$ and $\beta=+90^{\circ}$ (see Fig. 2). The effect of scanning geometry on $\varepsilon_{1}$ is such that $\varepsilon_{1}$ decreases with increasing arc span $(\Delta \theta)$ and decreasing beam number (or azimuth angles) per arc scan (Fig. 4). Enlarging $\Delta \theta$ increases the spatial coverage, and lowering the number of beams per arc scan increases the separation distance between samples, both of which reduce the correlation between samples and consequently the uncertainty in the estimated horizontal mean wind speed. Additionally, when $\Delta \theta$ increases and beam number decreases, the condition number of the matrix $\mathbf{G}$ in Eq. (6) decreases and, as a result, the uncertainty introduced by the inverse method (least squares method) decreases (Wang et al., 2015). The effect of scanning geometry on $\varepsilon_{1}$ naturally exhibits a dependence on the relative direction $(\beta)$. When the wind direction is parallel to the beams $\left(\beta=0^{\circ}\right), \varepsilon_{1}$ is weakly dependent on both arc span and beam number (Fig. 4a). For example, with a fixed beam number, $\varepsilon_{1}$ decreases by only $0.4 \%$ when increasing $\Delta \theta$ from 30 to $120^{\circ}$. When $\beta= \pm 45^{\circ}, \varepsilon_{1}$ is less sensitive to beam number than arc span (Fig. 4b). When $\beta= \pm 90^{\circ}, \varepsilon_{1}$ is more sensitive to beam number than arc span (Fig. $4 \mathrm{c}$ and d). Sensitivity is highest when $\beta=+90^{\circ}$ and $\Delta \theta<60^{\circ}$. When $\beta=+90^{\circ}$, there is a band of local minima with $\varepsilon_{1}<4 \%$ starting at $\Delta \theta=30^{\circ}$ and beam number 8 . The beam numbers and the arc spans associated with those minima are such that the distance between two adjacent azimuth angles is equal to the distance that wind travels when the lidar changes from one azimuth angle to the next one. In other words, under the frozen turbulence assumption the lidar samples the same location repetitively, causing the uncertainty to reduce. The uncertainty in wind speed derived from arc scans naturally causes uncertainty in determining the wind speed corresponding to a power output and consequently uncertainty in the measured power curve. If the power coefficient of the wind turbine is invariant with wind speed, the uncertainty in the measured power curve is $3 \varepsilon_{1}$ (because wind power is proportional to the cube of wind speed). Hence, neglecting other sources of uncertainty and error in wind turbine power performance test, such as shear across the swept area (Wagner

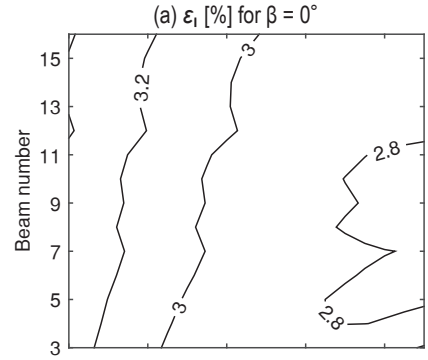

(c) $\varepsilon_{1}[\%]$ for $\beta=+90^{\circ}$

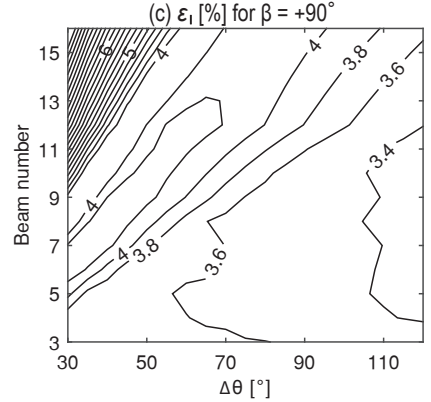

(b) $\varepsilon_{1}[\%]$ for $\beta=+45^{\circ}$

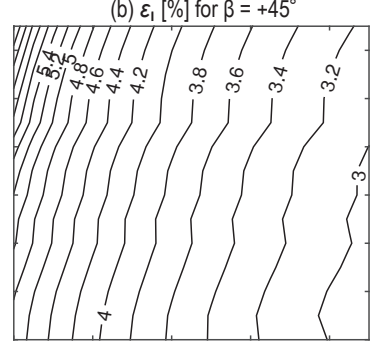

(d) $\varepsilon_{1}[\%]$ for $\beta=-90^{\circ}$

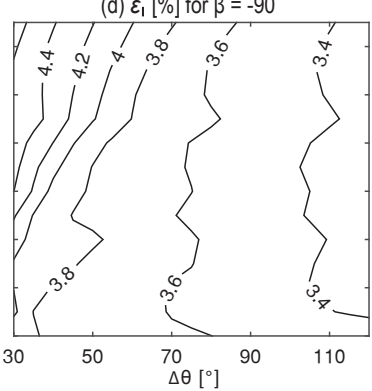

Figure 4. Dependence of relative standard error $\left(\varepsilon_{1}\right)$ of wind speed $\left(V_{0}\right)$ on arc span $(\Delta \theta)$ and beam number per arc scan for relative directions (a) $\beta=0^{\circ}$, (b) $\beta=+45^{\circ}$, (c) $\beta=+90^{\circ}$, and (d) $\beta=$ $-90^{\circ}$ with $\phi=16.7^{\circ}$ and $r=313 \mathrm{~m}$. The results are calculated for $V_{0}=7 \mathrm{~m} \mathrm{~s}^{-1}$ and $\mathrm{TI}=12 \%$ over a $10 \mathrm{~min}$ period. The Coriolis parameter $f_{0}=0.0001 \mathrm{~s}^{-1}$. The contour interval is $0.2 \%$.

et al., 2011), the analyses presented above imply that if the lidar beam is well aligned with the incoming "free stream", the uncertainty in the measured power curve derived from the wind speed measurement by lidar for this example turbine and wind speeds of $7-9 \mathrm{~m} \mathrm{~s}^{-1}$ is about $\pm 4 \%$ for a site with low turbulence intensity $(\mathrm{TI}=5 \%)$ and $\pm 20 \%$ for a high turbulence intensity environment $(\mathrm{TI}=20 \%)$. Though these values of uncertainty resulting from lidar arc scans are similar to the uncertainties in the power curve measured with cup anemometers with the same turbulence characteristics (Wyngaard, 2010), using lidar arc scans can eliminate the uncertainty of cup anemometer measurements caused by meteorological mast flow distortion, which has a typical value of $\pm 1 \%$ in wind speed and therefore $\pm 3 \%$ in wind power (IEC, 2005).

\section{Observed arc scan uncertainty}

The theoretical uncertainty from the isotropic turbulence model presented in the previous section is a useful tool for decomposing the uncertainty by source, and potentially to aid in planning lidar scan geometries prior to on-site deployment. It is used here to contextualize empirical analyses of the uncertainty on the mean wind velocity, turbulence statistics and scanning geometry using observational data derived from arc scans at three sites. Site names are not revealed because of confidentiality, but the site characteristics 


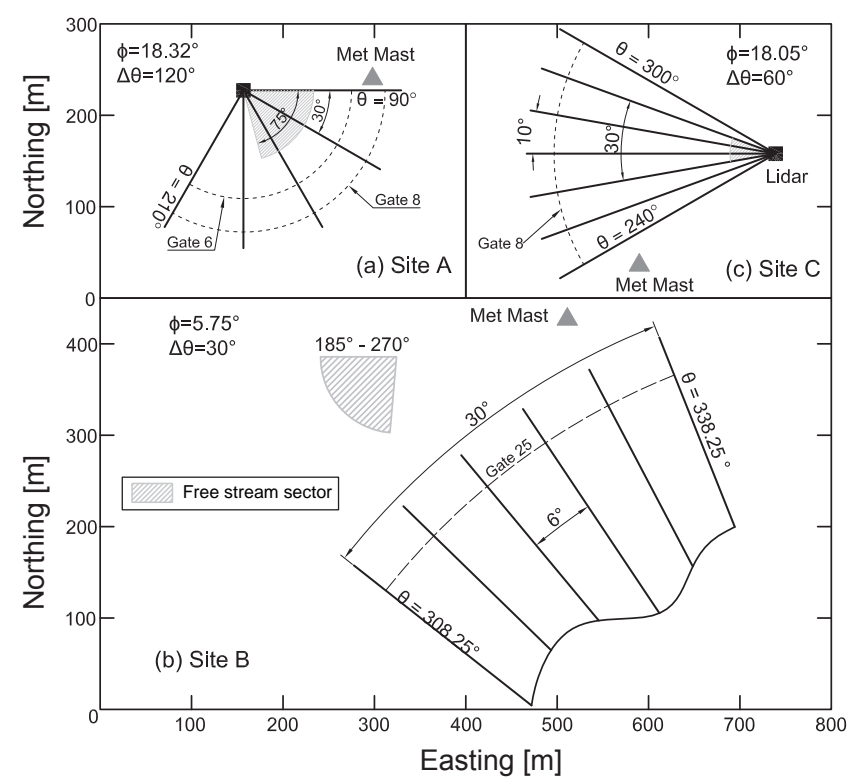

Figure 5. Plan views of the scanning geometries used at (a) Site A, (b) Site B and (c) Site C. The dark squares indicate the lidar locations, and the hatched areas indicate the wind direction sectors without flow distortions. Locations of meteorological masts are denoted by the solid gray circles. The elevation angle $(\phi)$ and the arc $\operatorname{span}(\Delta \theta)$ used at each of the sites are also given.

are provided below and the scan geometries are summarized in Fig. 5. In all cases the analysis is based on the estimated $10 \mathrm{~min}$ horizontal mean wind speed $\left(V_{1}\right)$ from the Galion measurements as derived using the ordinary least squares method. The RSE of $V_{1}$ will be evaluated through the relative difference $\left(e_{\mathrm{d}}\right)$ between $V_{1}$ and the measurement $\left(V_{\mathrm{c}}\right)$ from cup anemometers installed on nearby meteorological masts (in compliance with the standard, IEC, 2005):

$e_{\mathrm{d}}=\frac{V_{1}-V_{\mathrm{c}}}{V_{\mathrm{c}}}$.

Periods with $V_{\mathrm{c}}<4 \mathrm{~m} \mathrm{~s}^{-1}$ or lidar SNR $<-20 \mathrm{~dB}$ are excluded from the analysis. To quantify the measurement uncertainty, the observed RSE $\left(\hat{\varepsilon}_{\mathrm{d}}\right)$ is defined as the standard deviation of $e_{\mathrm{d}}$ binned by wind direction or turbulence intensity, and the $95 \%$ confidence interval, $\mathrm{CI}_{95}$, of $\hat{\varepsilon}_{\mathrm{d}}$ is estimated by (Ahn and Fessler, 2003):

$\mathrm{CI}_{95}=\hat{\varepsilon}_{\mathrm{d}} \pm 1.96 \hat{\varepsilon}_{\mathrm{d}} / \sqrt{2(n-1)}$,

where $n$ is the number of samples in a bin. Note that this definition means that only the spread of values is evaluated and bias is not considered.

The value of $\hat{\varepsilon}_{\mathrm{d}}$ has contributions from random errors related to both instrument and turbulence. The lidar instrument errors are not considered; hence, the expected $\operatorname{RSE}\left(\varepsilon_{\mathrm{d}}\right)$ based on the relative difference between lidar and cup anemometer measurements has the following definition:

$\varepsilon_{\mathrm{d}}^{2}=\varepsilon_{1}^{2}+\varepsilon_{\mathrm{c}}^{2}-2 \rho_{\mathrm{lc}} \varepsilon_{1} \varepsilon_{\mathrm{c}}+\varepsilon_{\text {cup }}^{2}$.
Table 2. Uncertainty classification of the cup anemometers used at the three sites.

\begin{tabular}{llll}
\hline Site & Cup Anemometer & IEC Class $^{1}$ & Class Number \\
\hline Site A & NRG 40C & A & $2.40^{2}$ \\
Site B & Vector L100 & A & $1.80^{2}$ \\
Site C & WindSensor P2546A & B & $3.71^{3}$ \\
\hline
\end{tabular}

${ }^{1}$ Class A is for sites with flat terrain and Class B is for sites with complex terrain (IEC, 2005). ${ }^{2}$ Pedersen et al. (2006). ${ }^{3}$ Cup anemometer manufacturer.

Terms on the right hand side (RHS) of Eq. (16) represent sources of errors and will be estimated as follows in order to differentiate the lidar RSE from the difference between lidar and cup anemometer measurements:

- $\varepsilon_{1}$ is the lidar RSE due to turbulence defined in Eq. (13) that can be estimated with the isotropic turbulence model.

- $\varepsilon_{\mathrm{c}}$ is the cup RSE due to turbulence, which is a function of the integral time scale and the sampling duration (Lenschow et al., 1994). Equation (13) in Lenschow et al. (1994) will be used to estimate $\varepsilon_{\mathrm{c}}$ by assuming that the streamwise velocity autocorrelation decays exponentially. The integral time scale is derived from the integral length scale $\left(L_{u}\right)$ in Eq. (A12) and the observed mean wind speed. The sampling duration is $10 \mathrm{~min}$.

- $\rho_{\mathrm{lc}}$ is the correlation between the turbulence-related errors of lidar and cup anemometers that depends on the spatial structure of turbulence and the distance between cup and lidar measurement locations. Estimating $\rho_{\mathrm{lc}}$ is difficult because lidar measures a volume and cup measures a point (or a line assuming frozen turbulence). A simple approximation is used here to estimate $\rho_{\mathrm{lc}}$. The separation distance is the distance between the center of an arc and the cup location which are $150 \mathrm{~m}$ for both Site A and Site B and $120 \mathrm{~m}$ for Site C. The correlation decays exponentially with the same integral length scale that is used to estimate $\varepsilon_{1}$ and $\varepsilon_{\mathrm{c}}$ at each site.

$-\varepsilon_{\text {cup }}$ is the instrument error that can be found from the following equation:

$$
\varepsilon_{\text {cup }}=\left(\frac{k}{\sqrt{3}}\right) \cdot\left(\frac{0.05 \mathrm{~m} \mathrm{~s}^{-1}}{V_{0}}+0.005\right) \text {, }
$$

where $k$ is the cup anemometer class number that represents the maximum relative error of a cup anemometer in turbulent wind fields (IEC, 2005; Pedersen et al., 2006). The $k$ values for cup anemometers used at the three sites are listed in Table 2. 

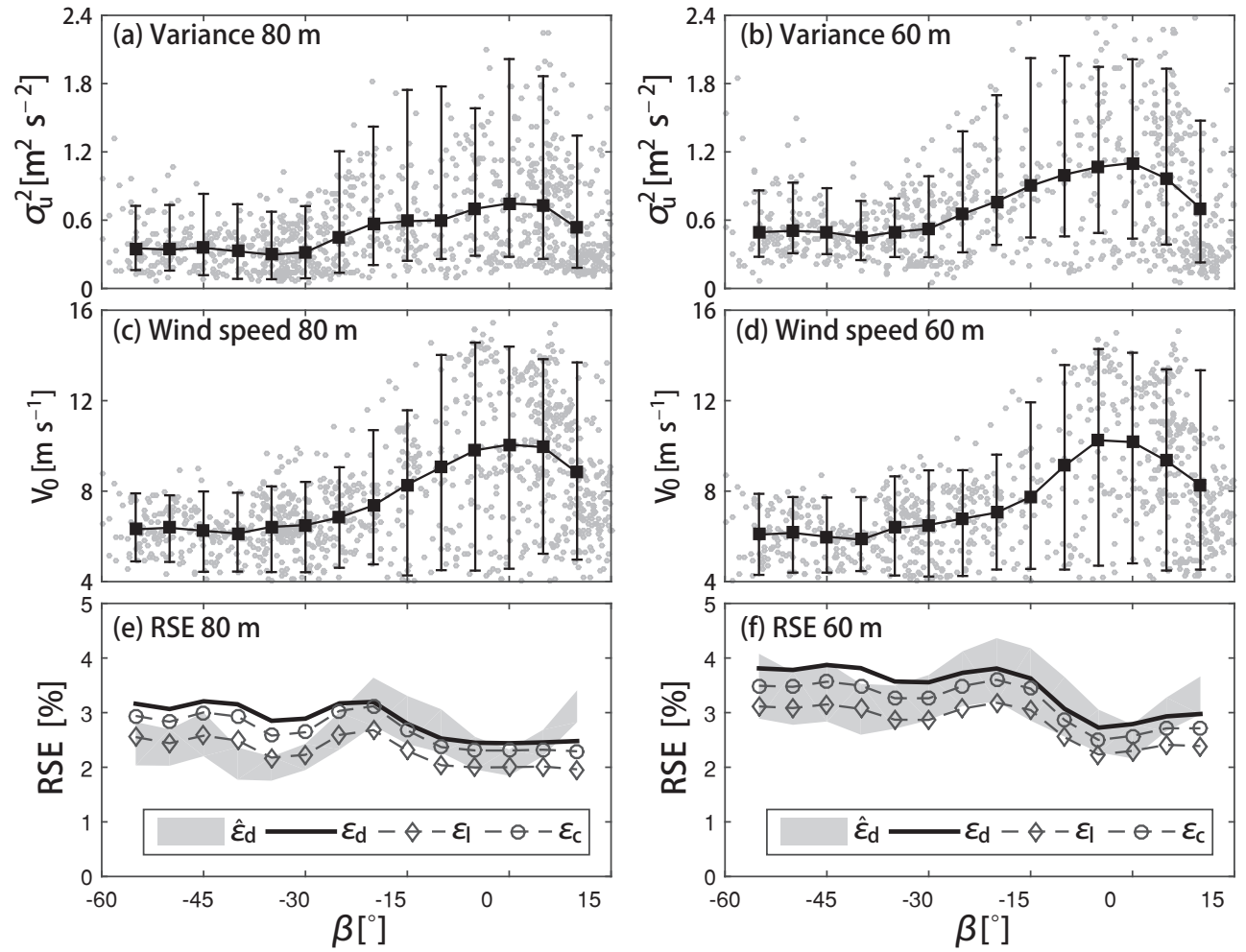

Figure 6. Variation of the standard error (RSE) with the relative direction $(\beta)$ at Site A at $80 \mathrm{~m}$ height in (a, c, e) and $60 \mathrm{~m}$ height in (b, d, f). The RSE is given in (e, f) for the $95 \%$ confidence interval of the observed difference between the cup and lidar measurements $\left(\hat{\varepsilon}_{\mathrm{d}}\right)$, the predicted difference between the cup and lidar measurements $\left(\varepsilon_{\mathrm{d}}\right)$, the predicted cup error $\left(\varepsilon_{\mathrm{c}}\right)$, and the predicted lidar error $\left(\varepsilon_{1}\right)$. The input for the RSE predictions include the mean wind speeds $\left(V_{0}\right)$ shown in $(\mathbf{c}, \mathbf{d})$ and the mean wind speed variance $\left(\sigma_{u}^{2}\right)$ shown in $(\mathbf{a}, \mathbf{b})$ for $80 \mathrm{~m}$ height and $60 \mathrm{~m}$ height, respectively.

\subsection{Site A}

Site $\mathrm{A}$ is a wind farm on a flat barren land, approximately $20 \mathrm{~km}$ from a coastline and at latitude $27^{\circ} \mathrm{N}$. The Galion lidar was operated for 20 days with arc scans centered at $\theta=150^{\circ}$ with $\Delta \theta=120^{\circ}, \delta \theta=30^{\circ}$ and $\phi=18.32^{\circ}$ (Fig. 5a). Wind speeds estimated from arc scan measurements at range gate 6 and 8 are evaluated against the concurrent data from cup anemometers installed on booms aligned southwest $\left(227^{\circ}\right)$ at $60 \mathrm{~m}$ height and $80 \mathrm{~m}$ height on a meteorological mast east of the lidar, respectively (Fig. 5a). Because of flow distortions from the wind turbines and the meteorological mast, the uncertainty evaluation is conducted only in the wind direction sector $90-165^{\circ}$ (based on the wind vane measurement at $77 \mathrm{~m}$ on the meteorological mast), resulting in 952 and 775 measurements of 10 minute mean wind speeds at 80 and $60 \mathrm{~m}$ height, respectively, and $100 \%$ recovery rate at both heights.

The observed RSE of relative difference $\left(\hat{\varepsilon}_{\mathrm{d}}\right)$ is calculated for $10^{\circ}$ bins of $\beta$ with $V_{\mathrm{c}}$ between 4 and $16 \mathrm{~m} \mathrm{~s}^{-1}$, and all terms on the RHS of Eq. (16) are estimated using the mean and variance of wind speed in each bin. The cup $\left(\varepsilon_{\mathcal{c}}\right)$ and lidar $\left(\varepsilon_{1}\right)$ RSE show similar dependence on the relative direction (Fig. 6), which is solely the result of variation of the mean and variance of wind speed with the relative direction. The directional dependence of arc scan RSE mentioned in Sect. 4 should be negligible because of the large arc span applied here. The fact that $\varepsilon_{1}<\varepsilon_{\mathrm{c}}$ in all direction bins (Fig. 6) supports the advantage of using large $\Delta \theta$ for arc scans. A large $\Delta \theta$ allows averaging over a large area, reducing the random error of mean wind speed. The expected RSE $\left(\varepsilon_{\mathrm{d}}\right)$, which combines both $\varepsilon_{1}$ and $\varepsilon_{\mathrm{c}}$ based on Eq. (16), agrees well with the observed RSE $\left(\hat{\varepsilon}_{\mathrm{d}}\right)$ except for some overestimation when $\beta<-20^{\circ}$ at $80 \mathrm{~m}$ height (Fig. 6). The consistency between $\hat{\varepsilon}_{\mathrm{d}}$ and $\varepsilon_{\mathrm{d}}$ at Site $\mathrm{A}$ indicates that turbulent wind fluctuations are the main source of uncertainty and those assumptions made in applying the isotropic turbulence model are largely realized.

\subsection{Site B}

Site B is an offshore wind farm at latitude $54.0^{\circ} \mathrm{N}$ at which the Galion lidar made arc scans for three months centered at $\theta=323.25^{\circ}$ with $\Delta \theta=30^{\circ}, \delta \theta=6^{\circ}$ and $\phi=5.75^{\circ}$. Wind speeds retrieved from range gate 25 are evaluated against concurrent cup anemometer measurements collected on a boom oriented at $135^{\circ}$ at $90 \mathrm{~m}$ on the meteorological mast north-northwest of the lidar (Fig. 5b). Observa- 
(a) Variance 8 - $12 \mathrm{~m} \mathrm{~s}^{-1}$

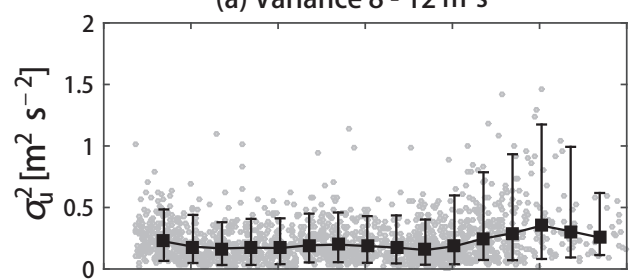

(c) Wind speed $8-12 \mathrm{~m} \mathrm{~s}^{-1}$
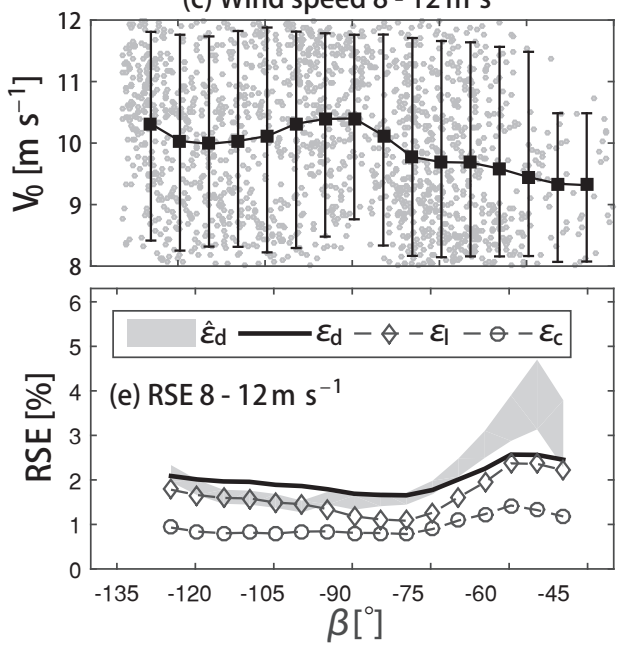

(b) Variance $12-16 \mathrm{~m} \mathrm{~s}^{-1}$

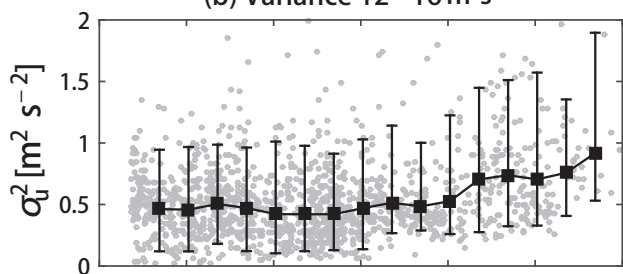

(d) Wind speed $12-16 \mathrm{~m} \mathrm{~s}^{-1}$
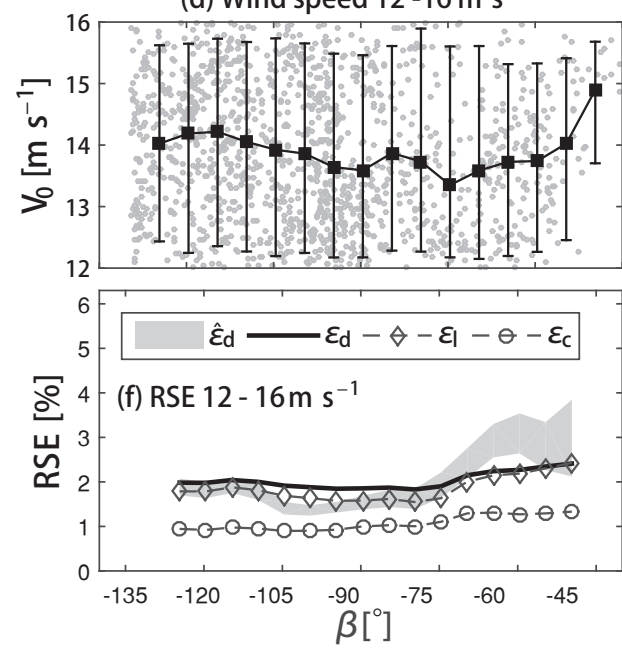

Figure 7. Variation of the standard error (RSE) with the relative direction $(\beta)$ at Site B for the wind speed bin $8-12 \mathrm{~m} \mathrm{~s}^{-1}$ in $(\mathbf{a}, \mathbf{c}, \mathbf{e})$ and the wind speed bin $12-16 \mathrm{~m} \mathrm{~s}^{-1}$ in $\left.\mathbf{( b ,}, \mathbf{d}, \mathbf{f}\right)$. The RSE is given in $(\mathbf{e}, \mathbf{f})$ for the $95 \%$ confidence interval of the observed difference between the cup and lidar measurements $\left(\hat{\varepsilon}_{\mathrm{d}}\right)$, the predicted difference between the cup and lidar measurements $\left(\varepsilon_{\mathrm{d}}\right)$, the predicted cup error $\left(\varepsilon_{\mathrm{c}}\right)$, and the predicted lidar error $\left(\varepsilon_{1}\right)$. The input for the RSE predictions include the mean wind speeds $\left(V_{0}\right)$ shown in $(\mathbf{c}, \mathbf{d})$ and the mean wind speed variance $\left(\sigma_{u}^{2}\right)$ shown in $(\mathbf{a}, \mathbf{b})$ for the wind speed bin 8-12 and $12-16 \mathrm{~m} \mathrm{~s}^{-1}$, respectively.

tions within a wind direction sector $185-270^{\circ}$ (2954 measurements of 10 min mean wind speeds with $97 \%$ data recovery rate) are used for analysis because of flow distortion from the wind turbines and the meteorological mast in the other sectors.

Data are stratified into two wind speed bins 8-12 and 12$16 \mathrm{~m} \mathrm{~s}^{-1}$ (based on $V_{\mathrm{c}}$ ), and are sampled in $10^{\circ}$ bins of $\beta$. In general there is a good agreement between the observed $\left(\hat{\varepsilon}_{\mathrm{d}}\right)$ and expected $\left(\varepsilon_{\mathrm{d}}\right)$ RSE (Fig. 7). Due to the small arc span applied at Site $\mathrm{B}, \varepsilon_{1}$ has higher dependence than $\varepsilon_{\mathrm{c}}$ on the relative direction $(\beta)$, and $\varepsilon_{1}>\varepsilon_{\mathrm{d}}$ (Fig. 7). It seems that $\hat{\varepsilon}_{\mathrm{d}}$ follows $\varepsilon_{1}$ when $\beta$ changes, while $\varepsilon_{\mathrm{c}}$ has little variation with $\beta$ (Fig. 7). The high $\hat{\varepsilon}_{\mathrm{d}}$ when $\beta>-70^{\circ}$ is likely caused by the high values of $\varepsilon_{1}$, although there could be other contributors such as wind turbine wakes and low sample size.

\subsection{Site C}

Site $\mathrm{C}$ is a wind farm located at latitude $38.1^{\circ} \mathrm{N}$ in relatively complex terrain. Arc scans were performed over 25 days centered at $\theta=270^{\circ}$ with $\Delta \theta=60^{\circ}, \delta \theta=10^{\circ}$ and $\phi=18.05^{\circ}$ (Fig. 5c). Wind speeds retrieved from range gate 8 are evaluated against measurements from a cup anemometer deployed on a boom oriented to $247.5^{\circ}$ at $80 \mathrm{~m}$ on the meteorological mast southwest of the lidar (Fig. 5c). There is no flow distortion in the wind direction sector $205-290^{\circ}$. However, because of orographic channeling, $95 \%$ of observations are associated with wind directions between 260 and $290^{\circ}$. Thus, this sector, which contains 2167 measurements of 10 min mean wind speed (93\% data recovery rate), is chosen for the uncertainty analysis.

Both observed $\left(\hat{\varepsilon}_{\mathrm{d}}\right)$ and expected $\left(\varepsilon_{\mathrm{d}}\right)$ RSE for $2^{\circ}$ bins of $\beta$ and wind speed between 6 and $14 \mathrm{~m} \mathrm{~s}^{-1}$ indicate a dependence on wind direction which derives largely from the directional variability of the mean and variance of wind speed (Fig. 8). $\hat{\varepsilon}_{\mathrm{d}}$ increases from $2 \%$ for $\beta \sim-10^{\circ}$ to nearly $4 \%$ at $\beta \sim+12^{\circ}$ in large part due to the decrease in mean wind speed (from 11 to $\sim 9 \mathrm{~m} \mathrm{~s}^{-1}$ ) and increase in variance (from $<0.6$ to nearly $1 \mathrm{~m}^{2} \mathrm{~s}^{-2}$ ). Though the agreement between $\hat{\varepsilon}_{\mathrm{d}}$ and $\varepsilon_{\mathrm{d}}$ is good, both $\varepsilon_{1}$ and $\varepsilon_{\mathrm{c}}$ are much lower than $\hat{\varepsilon}_{\mathrm{d}}$. It is the instrument error of cup ( $\left.\varepsilon_{\text {cup }}\right)$ that contributes the most to the difference between the lidar and cup measurements. The values of $\varepsilon_{1}$ and $\varepsilon_{\mathrm{c}}$ are very close. Note that $\varepsilon_{1}$ and $\varepsilon_{\mathrm{c}}$ should be lower than the actual values because non-homogeneous horizontal wind fields and non-zero vertical wind speeds over complex terrain violate assumptions in the theoretical models (Bingöl et al., 2009). 
(a) Variance

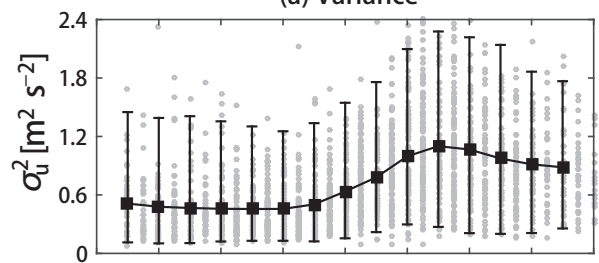

(b) Wind speed
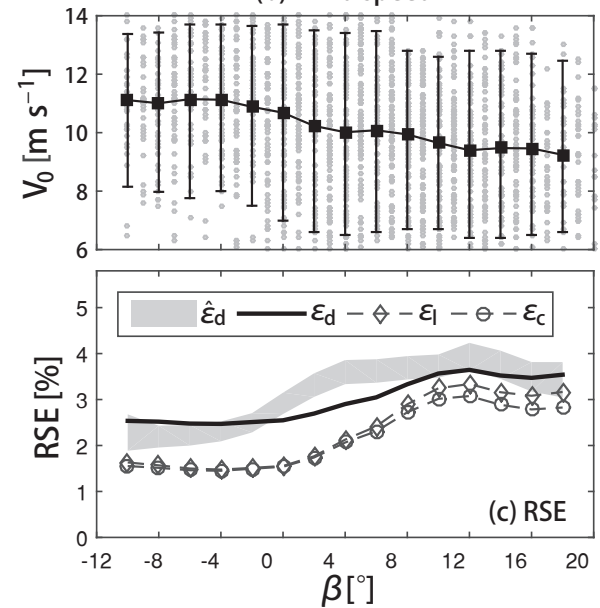

Figure 8. Variation of the standard error (RSE) with the relative direction $(\beta)$ at Site $\mathrm{C}$ at $80 \mathrm{~m}$ height. The RSE is given in (c) for the $95 \%$ confidence interval of the observed difference between the cup and lidar measurements $\left(\hat{\varepsilon}_{\mathrm{d}}\right)$, the predicted difference between the cup and lidar measurements $\left(\varepsilon_{\mathrm{d}}\right)$, the predicted cup error $\left(\varepsilon_{\mathrm{c}}\right)$, and the predicted lidar error $\left(\varepsilon_{1}\right)$. The input for the RSE predictions include the mean wind speeds $\left(V_{0}\right)$ shown in (b) and the mean wind speed variance $\left(\sigma_{u}^{2}\right)$ shown in (a).

\section{Discussion}

The isotropic turbulence model is not a true representation of the turbulent wind field in the atmosphere. The three wind components rarely have equal variance and the same turbulence integral length scale. Further, the exponential decay function is only an approximation of the turbulence autocorrelation function. Nevertheless, the analyses presented above indicate that when properly constrained, the isotropic turbulence model reproduces the uncertainty in wind speed estimated from arc scans with different scanning geometries at different sites, and the predicted relationship between RSE and turbulence intensity is also consistent with the observed relationship (Fig. 9). The effect of the arc span on the uncertainty of wind speed estimated from arc scans as presented based on the theoretical approach can also be verified by observations after they have been normalized to remove the effect of sample number, turbulence intensity and wind speed on the uncertainty to allow comparison across the sites. Thus the relative errors $\left(e_{\mathrm{d}}\right)$ are scaled using (Wyngaard, 2010):

$e_{\mathrm{dN}}=\frac{e_{\mathrm{d}}}{S_{1} \cdot S_{2} \cdot S_{3}}$

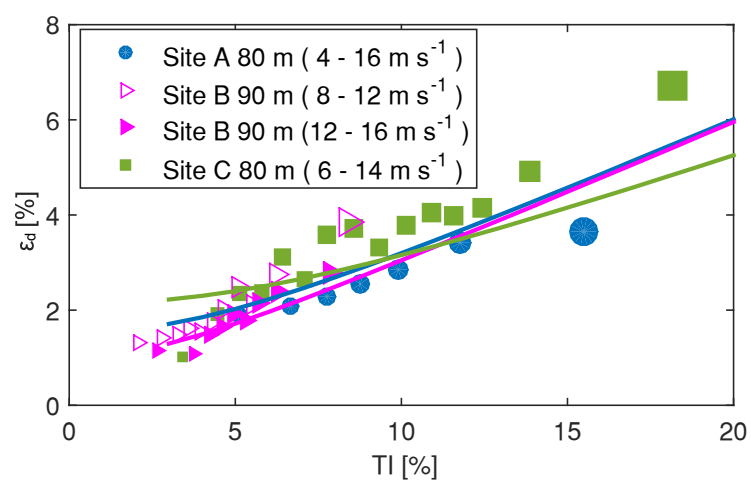

Figure 9. The relationship between the RSE of the relative difference between lidar and cup measurements $\left(\varepsilon_{\mathrm{d}}\right)$ and the turbulence intensity (TI) at the three sites. The $95 \%$ confidence interval for each observed RSE $\left(\hat{\varepsilon}_{\mathrm{d}}\right)$ is denoted by the marker size. The solid lines with matching colors are the predicted relationships at the sites. Prediction at Site A uses wind speed $8 \mathrm{~m} \mathrm{~s}^{-1}$ and wind direction $150^{\circ}$, at Site B wind speed $10 \mathrm{~m} \mathrm{~s}^{-1}$ and wind direction $323^{\circ}$, and at Site $\mathrm{C}$ wind speed $10 \mathrm{~m} \mathrm{~s}^{-1}$ and wind direction $270^{\circ}$. Values of $\varepsilon_{\mathrm{d}}$ here are derived from the cup errors related to the turbulence $\left(\varepsilon_{\mathrm{c}}\right)$ and instrument $\left(\varepsilon_{\text {cup }}\right)$, and the predicted lidar RSE $\left(\varepsilon_{1}\right)$ according to Eq. (16) and Table 2.

where

- $S_{1}=\left(M_{10}\right)^{-1 / 2}$ represents the relationship between the uncertainty and the sample number $M_{10}$ used to derive the mean horizontal wind speed.

$-S_{2}=\mathrm{TI}$ accounts for the fact that the uncertainty scales with turbulence intensity.

- $S_{3}=V_{0} \cdot L_{u} / 600 \mathrm{~s}$ represents the spatial coverage of a measurement over $600 \mathrm{~s}(10 \mathrm{~min})$ relative to the turbulence integral length scale.

The standard deviations of the errors, when $e_{\mathrm{dN}}$ is rescaled back to $e_{\mathrm{d}}$ with $V_{0}=9 \mathrm{~m} \mathrm{~s}^{-1}, \mathrm{TI}=12 \%\left(L_{u}=209 \mathrm{~m}\right.$ according to Appendix A) and $M_{10}=40$ using Eq. (18), are 2.0, 2.0 and $6.8 \%$ after being corrected for $\varepsilon_{\mathrm{c}}$ and $\varepsilon_{\text {cup }}$ according to Eq. (16) for Site A, Site C and Site B, respectively. In other words, the uncertainty increases when $\Delta \theta$ decreases from $120^{\circ}$ at Site A to $30^{\circ}$ at Site B, which is consistent with the predicted relationship between $\Delta \theta$ and RSE given in Fig. 4. This implies that the approach presented in Sects. 3 and 4 may be of great use for lidar scan geometry optimization for a given site. Note that the effect of $\beta$ has not been removed in the rescaling because an overlapping bin of $\beta$ with a sufficient sample number cannot be found at the three sites; therefore, the rescaling may change if $\beta$ is considered. 

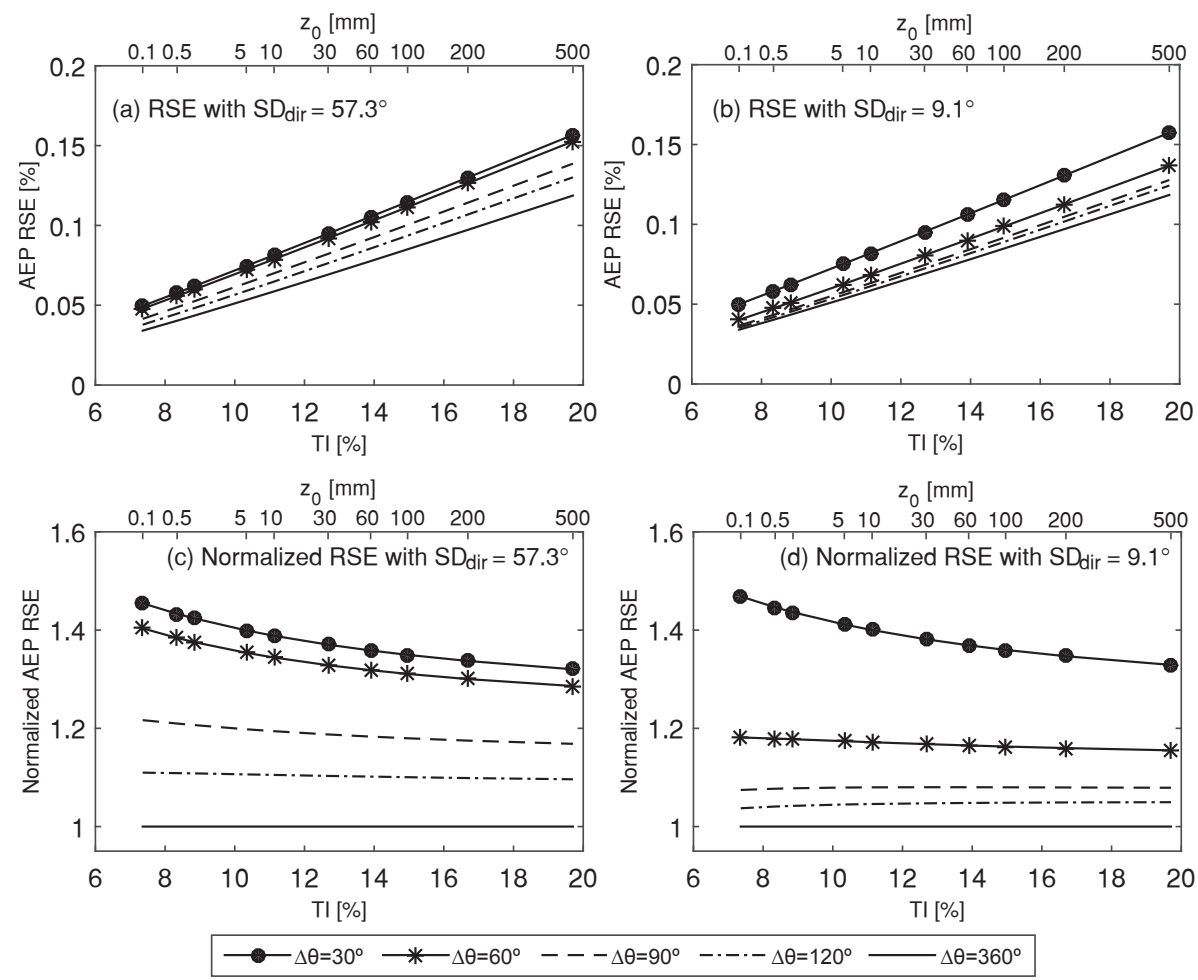

Figure 10. The relative standard error (RSE) in annual energy production (AEP) arising from arc scan velocity retrieval uncertainty as a function of turbulence intensity (TI) and surface roughness length $\left(z_{0}\right)$, assuming that wind speed follows a Rayleigh distribution with a mean of $7 \mathrm{~m} \mathrm{~s}^{-1}$, and wind direction follows the von Mises distributions with a mean of $90^{\circ}$ and standard deviations (SDdir) of $57.3^{\circ}$ in (a) and $9.1^{\circ}$ in (b). Four arc spans and a full azimuth conical scan (see the legend) are used for AEP prediction with six beams, $\phi=15^{\circ}$ and $r=315 \mathrm{~m}$. The normalized AEP RSE, which is the ratio of predicted AEP RSE from arc scans to that from the conical scan, is shown in $(\mathbf{c})$ for $\mathrm{SD}_{\mathrm{dir}}=57.3^{\circ}$ and in $(\mathbf{d})$ for $\mathrm{SD}_{\mathrm{dir}}=9.1^{\circ}$.

\section{Implications for applications in wind energy}

If wind speed measurements deriving from arc scans of a lidar are used to predict annual energy production (AEP) at a given site, naturally, the uncertainty in wind speeds will propagate into AEP prediction and contribute to the uncertainty in wind resource assessment. The annual AEP is predicted as follows:

$E_{\mathrm{y}}=\sum_{j=1}^{J} \sum_{i=1}^{I}\left(T_{\mathrm{y}} F_{\mathrm{V}, i} F_{\mathrm{D}, j}\right) P_{i}$,

where $F_{\mathrm{V}, i}$ and $F_{\mathrm{D}, j}$ are the probabilities of the $i$ th wind speed bin and $j$ th wind direction bin, respectively, $P_{i}$ is the power production of a wind turbine at wind speed $V_{i}$, and $T_{\mathrm{y}}$ is the total hours in a year. Assuming statistical independence between lidar measurements, the contribution of the arc scan measurement uncertainty to the uncertainty of $E_{\mathrm{y}}$ is quantified by the standard error $\left(\sigma_{\mathrm{y}}\right)$ defined as follows (IEC 2005):

$\sigma_{\mathrm{y}}^{2}=\sum_{j=1}^{J} \sum_{i=1}^{I}\left(T_{\mathrm{y}} F_{\mathrm{V}, i} F_{\mathrm{D}, j}\right) c_{i}^{2} \sigma_{1, i j}^{2}$, where $\sigma_{1, i j}$ is the lidar measurement standard error (see Eq. 9) for the $i$ th wind speed bin and $j$ th direction bin, and $c_{i}$ is the sensitivity factor determined by

$c_{i}=\left|\frac{P_{i}-P_{i-1}}{V_{i}-V_{i-1}}\right|$.

A scenario analysis of the resulting uncertainty in AEP prediction is commenced under the following assumptions: (1) the wind speed follows a Rayleigh distribution with a mean of $7 \mathrm{~m} \mathrm{~s}^{-1}$, (2) the wind direction follows a von Mises distribution with a mean of $90^{\circ}$ (see Appendix B for the probability density functions), (3) arc scans centered at $\theta=90^{\circ}$ with 6 beams, and $\phi=15^{\circ}$, and (4) the hub-height is $80 \mathrm{~m}$. Turbulence intensity and turbulence integral length scale are estimated from surface roughness length using Eqs. (A3) and (A12) in Appendix A, respectively.

The uncertainty in AEP prediction calculated using Eq. (20) and a power curve from a commercial wind turbine is shown in Fig. 10 for different arc spans, wind direction distributions, and surface roughness length values. Because of the large number of samples used for AEP prediction $\left(T_{\mathrm{y}}=8760\right)$, the AEP RSE defined as $\sigma_{\mathrm{y}} / E_{\mathrm{y}}$ is very low $(0.05-0.2 \%)$. The uncertainty in AEP increases linearly with 
TI (and hence $z_{0}$ ) and decreases with increasing arc span, but is not sensitive to the wind direction variation. The normalized AEP RSE, which is the ratio of the AEP RSE of arc scans to that of 6-beam conical scans (or $\Delta \theta=360^{\circ}$ ), has the highest value of about 1.4 for $\Delta \theta=30^{\circ}$ (Fig. $10 \mathrm{c}$ and d). Note the uncertainty of conical scans is the minimum value of uncertainty that arc scans can achieve (as a result of $\left.\Delta \theta \rightarrow 360^{\circ}\right)$.

\section{Conclusions}

Wind speeds measured by lidars are subject to uncertainties that originate from prevailing atmospheric conditions, lidar scanning geometry and wind velocity retrieval method. The analyses presented herein assume horizontal homogeneity and zero mean vertical speed, and thus neglect their roles in dictating optimal lidar operation. The effects of atmospheric turbulence properties and scanning geometry on the uncertainty in the wind speed estimated from lidar arc scans are investigated with both theoretical predictions and actual observations. The theoretical predictions are based on the frozen turbulence hypothesis and an isotropic turbulence model, and the actual observations include arc scan measurements from different scanning geometries both onshore and offshore. The predictions and the observations are consistent, and may be summarized as follows.

- The uncertainty can be scaled with the turbulence intensity.

- The lowest uncertainty can be achieved by aligning the line of sight with the wind direction. The highest uncertainty occurs when the wind direction is $45^{\circ}$ relative to the line of sight. There is a local minimum of uncertainty when the line of sight at the center of arc is orthogonal to the wind direction. However, it should be noted that radial velocities measured from orthogonal scans are zero.
- The uncertainty can generally be reduced by increasing arc span and decreasing beam number, although a minimum number of beams is required to characterize the wind velocity. The reduction is most significant when the relative angle between wind direction and line of sight is $45^{\circ}$. If the relative angle is close to zero, adjusting scan geometry will not change the uncertainty significantly. With orthogonal scans, the uncertainty is more sensitive to beam number than arc span.

- When arc scans are used for wind resource assessment, the uncertainty in annual energy production prediction arising from uncertainty in arc scan velocity retrieval is negligible. The uncertainty decreases with decreasing surface roughness and turbulence intensity, and increasing arc span.

The uncertainty estimation approach developed in this paper on the basis of the isotropic turbulence model, though is subject to limits and caveats, is able to predict the effect of wind velocity, turbulence intensity and scan geometry on the arc scan uncertainty at the three sites presented herein. Thus, this approach, although it needs to be further validated by more measurements, may have great utility for a priori optimization of lidar scan geometries for a given site. 


\section{Appendix A: Atmospheric boundary layer turbulence characteristics}

In the neutrally stratified surface layer of the atmospheric boundary layer (ABL), the vertical profile of horizontal wind speed is given by the logarithmic wind profile (Stull, 1988):

$V_{0}(z)=\frac{u_{*}}{\kappa} \ln \left(\frac{z}{z_{0}}\right)$,

where $u_{*}$ is surface friction velocity, $z_{0}$ is surface roughness length, $\kappa=0.4$ is the von Kármán constant and $z$ is height above the ground. The standard deviation of the horizontal wind speed $\left(\sigma_{u}\right)$ normalized by the friction velocity is a constant; that is,

$\frac{\sigma_{u}}{u_{*}}=c_{n}$

where constant $c_{n}=2.5$ (Stull, 1988). Hence, according to Eqs. (A1) and (A2), turbulence intensity, defined as $\mathrm{TI}=$ $\sigma_{u} / V_{0}$ can be estimated using the following equation:

$\mathrm{TI}=\frac{c_{n} \kappa}{\ln \left(z / z_{0}\right)}$.

The turbulence integral length scale is defined as

$L_{u}=\frac{1}{\sigma_{u}^{2}} \int_{0}^{+\infty} c_{u}(p) \mathrm{d} p$,

where $c_{u}$ is the spatial covariance function of streamwise velocity. Based on the von Kármán model and the Kolmogorov's 5/3 law, for turbulence with high wave numbers (e.g., turbulence in the inertial subrange), $L_{u}$ in the atmospheric surface layer $\left(L_{\mathrm{us}}\right)$ is defined as

$L_{\mathrm{us}}=c_{1} \frac{\sigma_{u}^{3}}{\varepsilon_{\mathrm{T}}}$,

where $c_{1}=0.7$ (Banakh et al., 1995; Frehlich and Cornman, 2002). The turbulence kinetic energy dissipation rate $\left(\varepsilon_{\mathrm{T}}\right)$ is related to the dimensionless dissipation rate $\left(\phi_{\varepsilon}\right)$ via the following equation:

$\varepsilon_{\mathrm{T}}=\frac{\phi_{\varepsilon} u_{*}^{3}}{\kappa z}$.

For a neutrally stratified atmosphere $\phi_{\varepsilon}=1$ (Panofsky and Dutton, 1984). Thus, combining Eqs. (A2), (A5) and (A6) yields a linear relationship between the turbulence integral length scale and height in the neutrally stratified surface layer:

$L_{\mathrm{us}}=c_{1} c_{n}^{3} \kappa z$.

The actual turbulence integral length scale in the ABL is constrained by the ABL height $\left(z_{i}\right)$ and the following equation can be used to account for the effect of $z_{i}$ on $L_{u}$ :

$L_{u}(z)=\frac{L_{\mathrm{us}}(z)}{1+c_{2} \frac{L_{\mathrm{us}}(z)}{z_{i}}}$, where $c_{2}=2.5$ (Blackadar, 1962; Banakh et al., 1995). The height of the neutrally stratified ABL can be determined using the following equation:

$z_{i}=c_{z} \frac{u_{*}}{f_{0}}$

where the coefficient $c_{z}=0.07-0.3$ in the literature (Seibert et al., 2000) and we use $c_{z}=0.3$ in this paper. The term $f_{0}$ is the Coriolis parameter and defined as

$f_{0}=2 \Omega \sin \phi_{\mathrm{L}}$

where $\phi_{\mathrm{L}}$ is the latitude and $\Omega=7.292 \times 10^{-5} \mathrm{rads}^{-1}$ is the angular speed of the Earth. Combing Eqs. (A2), (A7) and (A8) yields the following formula:

$L_{u}=\frac{c_{1} c_{n}^{3} \kappa z}{1+\frac{\kappa c_{1} c_{2} c_{n}^{4}}{c_{z}} \frac{f_{0} z}{\sigma_{u}}}$.

Using the values assigned to these empirical coefficients, $L_{u}$ can be calculated using the following equation:

$L_{u}=\frac{4.375 z \sigma_{u}}{\sigma_{u}+91.146 f_{0} z}$.

\section{Appendix B: Wind speed and direction probability distributions}

The wind speed distribution can be modeled using the Rayleigh distribution with the following probability density function (Forbes et al., 2011):

$f_{\mathrm{V}}(V)=\frac{2 V}{A^{2}} \exp \left[-\left(\frac{V}{A}\right)^{2}\right]$,

where $A$ is the scale factor.

The wind direction distribution can be modeled by the von Mises distribution with the following probability density function (Forbes et al., 2011):

$f_{\mathrm{D}}(D)=\frac{\exp [b \cos (D-\bar{D})]}{2 \pi I_{0}(b)}$,

where $D \in[0,2 \pi]$ is wind direction, $\bar{D}$ is the mean wind direction, $b$ is the concentration parameter, and $I_{0}(\cdot)$ is the modified Bessel function of the first kind of order zero. The circular standard deviation $\left(\sigma_{\mathrm{D}}^{2}\right)$ of the wind direction is then defined as

$\sigma_{\mathrm{D}}^{2}=1-I_{1}(b) / I_{0}(b)$,

where $I_{1}(\cdot)$ is the modified Bessel function of the first kind of order one. 


\section{Appendix C}

Table C1. Nomenclature.

\begin{tabular}{|c|c|}
\hline $\mathbf{A}$ & Covariance matrix of the measured radial velocities $\left[\mathrm{m}^{2} \mathrm{~s}^{-2}\right]$ \\
\hline$A$ & Rayleigh distribution scale factor $\left[\mathrm{ms}^{-1}\right]$ \\
\hline $\mathbf{C}$ & Wind velocity covariance matrix $\left[\mathrm{m}^{2} \mathrm{~s}^{-2}\right]$ \\
\hline $\mathbf{C}_{1}$ & Covariance matrix of the estimated horizontal wind vector $\left[\mathrm{m}^{2} \mathrm{~s}^{-2}\right]$ \\
\hline $\mathrm{CI}_{95}$ & $95 \%$ confidence interval \\
\hline$D$ & Wind direction $\left[{ }^{\circ}\right]$ \\
\hline $\mathbf{D}$ & A $N \times 2$ matrix with its $i$ th row given by $\left[\cos \phi \sin \theta_{i} \cos \phi \cos \theta_{i}\right]$ \\
\hline $\bar{D}$ & Annual mean wind direction $\left[{ }^{\circ}\right]$ \\
\hline$E_{\mathrm{y}}$ & Annual energy production $[\mathrm{J}]$ \\
\hline$F_{\mathrm{D}}$ & Wind direction probability \\
\hline$F_{\mathrm{V}}$ & Wind speed probability \\
\hline $\mathbf{G}$ & A $2 \times N$ matrix defined as $\left(\mathbf{D}^{T} \mathbf{D}\right)^{-1} \mathbf{D}^{T}$ \\
\hline I & Identity matrix \\
\hline$I_{k}$ & Bessel function of the first kind of order $k$ \\
\hline$\tilde{K}_{\mathrm{r}}$ & Covariance between two point radial velocities $\left[\mathrm{m}^{2} \mathrm{~s}^{-2}\right]$ \\
\hline$L_{u}$ & Turbulence integral length scale in the atmospheric boundary layer [m] \\
\hline$L_{\mathrm{us}}$ & Turbulence integral length scale in the surface layer [m] \\
\hline$M_{10}$ & Number of arc scans over a $10 \mathrm{~min}$ period \\
\hline$M_{\theta}$ & Number of azimuth angles per arc scan \\
\hline$N$ & Number of radial velocities measured over a $10 \mathrm{~min}$ period \\
\hline$P$ & Wind turbine power production $[\mathrm{W}]$ \\
\hline$T_{\mathrm{y}}$ & Total hours in a year \\
\hline$V_{1}$ & Estimated mean horizontal wind velocity vector from arc scans $\left[\mathrm{ms}^{-1}\right]$ \\
\hline$V_{0}$ & Horizontal mean wind speed $\left[\mathrm{ms}^{-1}\right]$ \\
\hline$V_{1}$ & Estimated horizontal mean wind speed from arc scans $\left[\mathrm{ms}^{-1}\right]$ \\
\hline$V_{\mathrm{c}}$ & Horizontal mean wind speed from cup anemometers $\left[\mathrm{m} \mathrm{s}^{-1}\right]$ \\
\hline$W$ & Lidar weighting function \\
\hline$a$ & Covariance between two measured radial velocities $\left[\mathrm{m}^{2} \mathrm{~s}^{-2}\right]$ \\
\hline$b$ & von Mises distribution concentration parameter \\
\hline$c$ & Wind power sensitivity factor due to wind speed uncertainty $\left[\mathrm{kg} \mathrm{m} \mathrm{s}^{-2}\right]$ \\
\hline$c_{\mathrm{lk}}$ & An entry of $\mathbf{C}\left[\mathrm{m}^{2} \mathrm{~s}^{-2}\right]$ \\
\hline$c_{u}$ & Spatial covariance of the streamwise wind component $\left[\mathrm{m}^{2} \mathrm{~s}^{-2}\right]$ \\
\hline$d$ & Unit directional vector of the line-of-sight of lidar \\
\hline$e$ & Radial velocity measurement random error $\left[\mathrm{m} \mathrm{s}^{-1}\right]$ \\
\hline$e_{\mathrm{d}}$ & Relative difference between lidar and cup anemometer measurements \\
\hline$e_{\mathrm{rd}}$ & Normalized $e_{\mathrm{d}}$ \\
\hline$f_{0}$ & Coriolis parameter $\left[\mathrm{s}^{-1}\right]$ \\
\hline$f_{\mathrm{D}}$ & Wind direction probability density function \\
\hline$f_{\mathrm{V}}$ & Wind speed probability density function \\
\hline$k$ & Cup anemometer classification number \\
\hline$n$ & Number of samples \\
\hline$p$ & Separation distance vector between two measured radial velocities [m] \\
\hline$q$ & Separation distance vector between two point radial velocities [m] \\
\hline$q$ & Separation distance between two point radial velocities [m] \\
\hline$q_{1}$ & Separation distance in the streamwise direction $[\mathrm{m}]$ \\
\hline$q_{2}$ & Separation distance in the transverse direction $[\mathrm{m}]$ \\
\hline$q_{3}$ & Separation distance in the vertical direction [m] \\
\hline$r$ & Lidar range gate position vector $[\mathrm{m}]$ \\
\hline$r$ & Lidar range gate location on the LOS $[\mathrm{m}]$ \\
\hline$s$ & Point radial velocity position vector $[\mathrm{m}]$ \\
\hline$s$ & Point radial velocity location on the LOS $[\mathrm{m}]$ \\
\hline
\end{tabular}


Table C1. Continued.

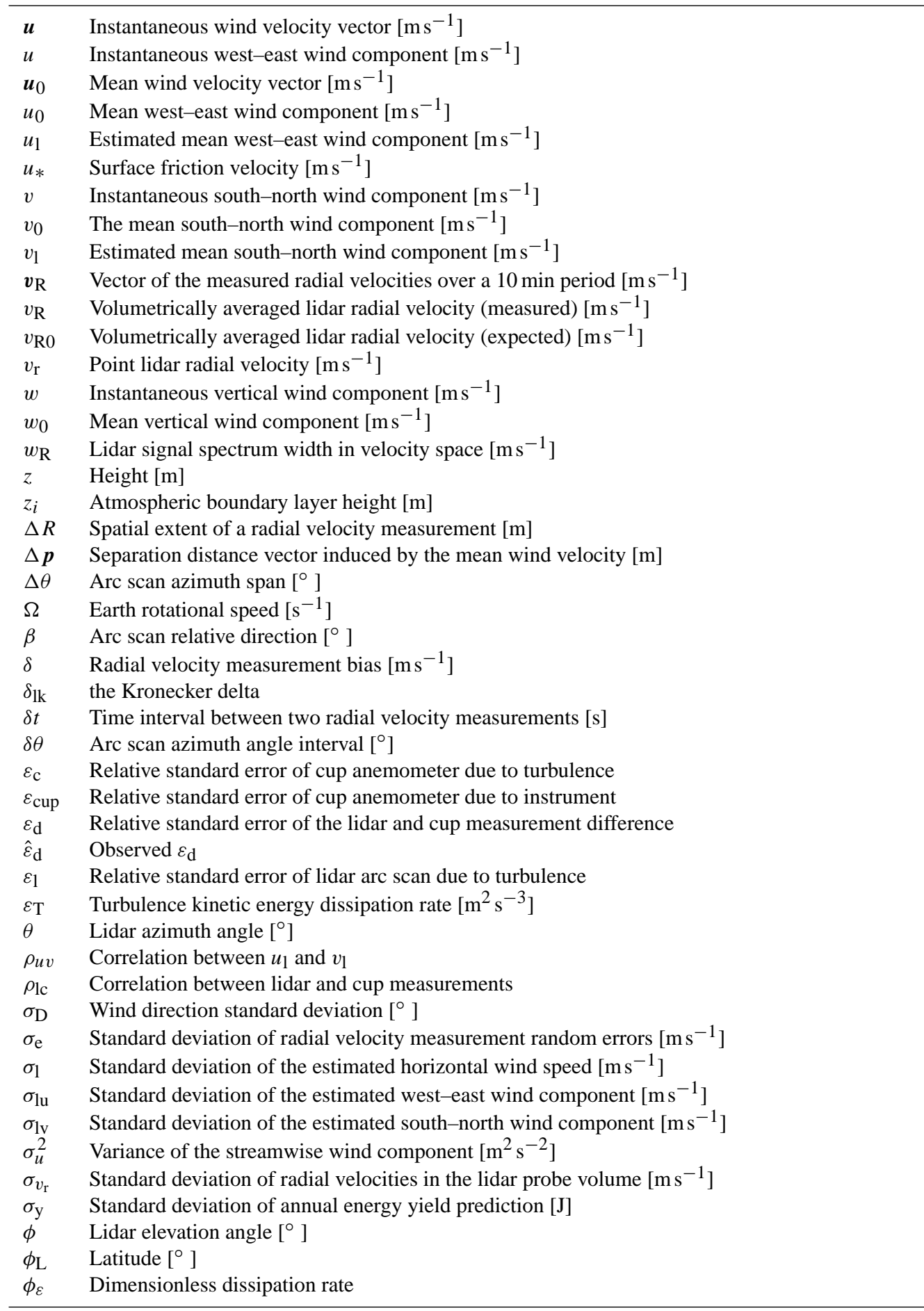


Acknowledgements. This work was funded by the US National Science Foundation under award no. 1464383 and the US Department of Energy under award no. DE-EE0005379. The article process charge was funded by the Cornell Open Access Publication Fund. The insightful comments from the reviewers are acknowledged.

Edited by: U. Wandinger

\section{References}

Ahn, S. and Fessler, J. A.: Standard Errors of Mean, Variance, and Standard Deviation Estimators, available at: http://ai.eecs. umich.edu/ fessler/papers/files/tr/stderr.pdf (last access: 1 October 2015), University of Michigan, Communication and Signal Processing Lab, Department of EECS, Ann Arbor, Michigan, 2003.

Aitken, M. L., Banta, R. M., Pichugina, Y. L., and Lundquist, J. K.: Quantifying wind turbine wake characteristics from scanning remote sensor data, J. Atmos. Ocean. Tech., 31, 765-787, doi:10.1175/JTECH-D-13-00104.1, 2014.

Banakh, V. A., Smalikho, I. N., Köpp, F., and Werner, C.: Representativeness of wind measurements with a cw Doppler lidar inthe atmospheric boundary layer, Appl. Optics, 34, 2055-2067, doi:10.1364/AO.34.002055, 1995.

Banta, R. M., Pichugina, Y. L., Kelley, N. D., Jonkman, B., and Brewer, W. A.: Doppler lidar measurements of the great plains low-level jet: applications to wind energy, IOP C. Ser. Earth Env., 1, 12-20, 2008.

Banta, R. M., Pichugina, Y. L., Kelley, N. D., Hardesty, R. M., and Brewer, W. A.: Wind energy meteorology: insight into wind properties in the turbine-rotor layer of the atmosphere from highresolution Doppler lidar, B. Am. Meteorol. Soc., 94, 883-902, doi:10.1175/BAMS-D-11-00057.1, 2013.

Barthelmie, R. J., Crippa, P., Wang, H., Smith, C. M., Krishnamurthy, R., Choukulkar, A., Calhoun, R., Valyou, D., Marzocca, P., Matthiesen, D., Brown, G., and Pryor, S. C.: 3-D wind and turbulence characteristics of the atmospheric boundary layer, B. Am. Meteorol. Soc., 95, 743-756, doi:10.1175/BAMS-D-1200111.1, 2013.

Bingöl, F., Mann, J., and Foussekis, D.: Conically scanning lidar error in complex terrain, Meteorol. Z., 18, 189-195, 2009.

Blackadar, A. K.: The vertical distribution of wind and turbulent exchange in a neutral atmosphere, J. Geophys. Res., 67, 30953102, doi:10.1029/JZ067i008p03095, 1962.

Calhoun, R., Heap, R., Princevac, M., Newsom, R., Fernando, H., and Ligon, D.: Virtual towers using coherent Doppler lidar during the Joint Urban 2003 Dispersion Experiment, J. Appl. Meteorol. Clim., 45, 1116-1126, doi:10.1175/JAM2391.1, 2006.

Choukulkar, A., Calhoun, R., Billings, B., and Doyle, J.: Investigation of a complex nocturnal flow in Owens Valley, California using coherent Doppler lidar, Bound.-Lay. Meteorol., 144, 359378, 2012.

Courtney, M., Peña, A., Wagner, R., Peeringa, J., Brand, A., Gottschall, J., Rettenmeir, A., and Pierella, F.: D4.06 Data Reports and Databases: Data on Coastal and Offshore Wind Measurements, 42, available at: http://www.fp7-marinet.eu/public/ docs/D4.06\%20Data\%20reports\%20and\%20databases.pdf (last access: 1 October 2015), MARINET, Cork, Ireland, 2014.
Forbes, C., Evans, M., Hastings, N., and Peacock, B.: Statistical Distributions, John Wiley \& Sons, Hoboken, New Jersey, 230 pp., 2011.

Frehlich, R.: Effects of wind turbulence on coherent Doppler lidar performance, J. Atmos. Ocean. Tech., 14, 54-75, 1997.

Frehlich, R.: Estimation of velocity error for Doppler lidar measurements, J. Atmos. Ocean. Tech., 18, 1628-1639, 2001.

Frehlich, R. and Cornman, L.: Estimating spatial velocity statistics with coherent Doppler lidar, J. Atmos. Ocean. Tech., 19, 355366, doi:10.1175/1520-0426-19.3.355, 2002.

Frehlich, R. and Yadlowsky, M.: Performance of mean-frequency estimators for Doppler radar and lidar, J. Atmos. Ocean. Tech., 11, 1217-1230, 1994.

Frehlich, R., Meillier, Y., Jensen, M. L., Balsley, B., and Sharman, R.: Measurements of boundary layer profiles in an urban environment, J. Appl. Meteorol. Clim., 45, 821-837, doi:10.1175/JAM2368.1, 2006.

Gottschall, J., Courtney, M. S., Wagner, R., Jørgensen, H. E., and Antoniou, I.: Lidar profilers in the context of wind energy a verification procedure for traceable measurements, Wind Energy, 15, 147-159, doi:10.1002/we.518, 2012.

Henke, M. and Clive, P.: Robust low cost offshore power curve tests with LiDAR, in: EWEA Offshore 2015, 172, Copenhagen, Denmark, 10-12 March 2015.

IEC: IEC 61400-12-1: 2005 Wind turbines - Part 12-1: Power Performance Measurements of Electricity Producing Wind Turbines, Geneva, Switzerland, 90 pp., 2005.

Krishnamurthy, R., Calhoun, R., Billings, B., and Doyle, J.: Wind turbulence estimates in a valley by coherent Doppler lidar, Meteorol. Appl., 18, 361-371, doi:10.1002/met.263, 2011.

Krishnamurthy, R., Choukulkar, A., Calhoun, R., Fine, J., Oliver, A., and Barr, K. S.: Coherent Doppler lidar for wind farm characterization, Wind Energy, 16, 189-206, doi:10.1002/we.539, 2013.

Lenschow, D. H., Mann, J., and Kristensen, L.: How long is long enough when measuring fluxes and other turbulence statistics?, J. Atmos. Ocean. Tech., 11, 661-673, doi:10.1175/15200426(1994)011<0661:HLILEW>2.0.CO;2, 1994.

Lindelöw, P., Courtney, M., Parmentier, R., and Cariou, J.: Wind shear proportional errors in the horizontal wind speed sensed by focused, range gated lidars, IOP C. Ser. Earth Env., 1, 012023, doi:10.1088/1755-1315/1/1/012023, 2008.

Lyons, L.: A Practical Guide to Data Analysis for Physical Science Students, Cambridge University Press, Cambridge, UK, 95 pp., 1991.

Monin, A. S. and Yaglom, A. M.: Statistical Hydromechanics, Nauka, Moscow, 1965.

Panofsky, H. A. and Dutton, J. A.: Atmospheric turbulence: models and methods for engineering applications, John Wiley \& Sons, New York, USA, 1984.

Pedersen, F. T., Dahlberg, J.-Å., and Busche, P.: ACCUWINDClassification of Five Cup Anemometers According to IEC 61400-12-1, Forskningscenter Risøe, Denmark, Risøe-R, No. 1556(EN), 2006.

Pearson, G. N. and Collier, C. G.: A pulsed coherent $\mathrm{CO}_{2}$ lidar for boundary-layer meteorology, Q. J. Roy. Meteor. Soc., 125, $2703-$ 2721, doi:10.1002/qj.49712555918, 1999.

Pichugina, Y. L., Banta, R. M., Brewer, W. A., Sandberg, S. P., and Hardesty, R. M.: Doppler lidar-based wind-profile measure- 
ment system for offshore wind-energy and other marine boundary layer applications, J. Appl. Meteorol. Clim., 51, 327-349, 2012.

Schwiesow, R., Köpp, P., and Werner, C.: Comparison of CW-lidarmeasured wind values obtained by full conical scan, conical sector scan and two-point techniques, J. Atmos. Ocean. Tech., 2, 3-14, 1985.

Seibert, P., Beyrich, F., Gryning, S.-E., Joffre, S., Rasmussen, A., and Tercier, P.: Review and intercomparison of operational methods for the determination of the mixing height, Atmos. Environ., 34, 1001-1027, 2000.

Simley, E., Pao, L. Y., Frehlich, R., Jonkman, B., and Kelley, N.: Analysis of light detection and ranging wind speed measurements for wind turbine control, Wind Energy, 17, 413-433, doi:10.1002/we.1584, 2013.
Stull, R. B.: An Introduction to Boundary Layer Meteorology, Springer Science \& Business Media, Dordrecht, the Netherlands, 670 pp., 1988.

Wagner, R., Courtney, M., Gottschall, J., and LindelöwMarsden, P.: Accounting for the speed shear in wind turbine power performance measurement, Wind Energy, 14, 993-1004, doi:10.1002/we.509, 2011.

Wang, H., Barthelmie, R. J., Clifton, A., and Pryor, S. C.: Wind measurements from arc scans with Doppler wind lidar, J. Atmos. Ocean. Tech., 11, 2024-2040, doi:10.1175/JTECH-D-1400059.1, 2015.

Wyngaard, J. C.: Turbulence in the Atmosphere, Cambridge University Press, Cambridge, UK, 406 pp., 2010. 